

\section{Sumário}

I. INTRODUÇÃO

The Datasphere and the Law: New Space, New Territories ...................................III Jean-Sylvestre Bergé e Stéphane Grumbach

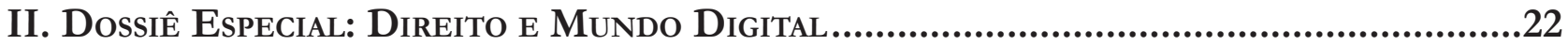

A. Criptomoedas e tecnologia blockchain ......................................................................23

Passado, presente e futuro da CRiptografia forte: DesenVolvimento tecnológico e

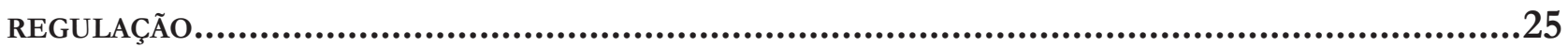
Jacqueline de Souza Abreu

Tratamento JuRídico Das CRIPTOMOEDAS: A DiNÂMiCA DOS BitCOINS E O CRIME DE LAVAGEM

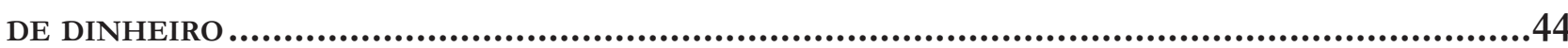
Mariana Dionísio de Andrade

TERRITÓRIO DAS CRIPTOMOEDAS: LIMITES À REGULAMENTAÇÃo ESTATAL QUANTO À CIRCULAÇÃO DE MOEDAS NO CIBERESPAÇO E POSSÍvEIS ALTERNATIVAS ..................................................61 Ranidson Gleyck Amâncio Souza

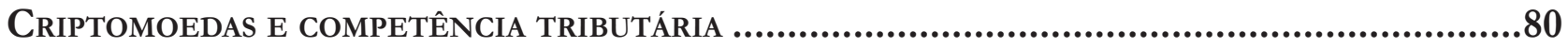
Guilherme Broto Follador

BitCoIn E A (IM)POSSIBILIDAde DE SUA PROIBIÇÃO: UMA VIOLAÇÃo À SOBERANIA Do EsTAdo?106 Rodrigo Valente Giublin Teixeira e Felipe Rangel da Silva

BlockChain e Agenda 2030

Danielle Mendes Thame Denny, Roberto Ferreira Paulo e Douglas de Castro

A reconstruÇão da JURISDição PELO ESPAÇO Digital: REDES SOCIAIS, BLOCKCHAIN E CRIPTOMOEDAS COMO PROPULSORES DA MUDANÇA.

Maria Edelvacy Pinto Marinho e Gustavo Ferreira Ribeiro

B. Proteção de dados e provedores de Internet

O tempo e O espaço. Fragmentos do marco Civil da internet: paradigmas de Proteção DA DIGNIDADE HUMANA 160 Maria Celeste Cordeiro Leite dos Santos e Marilene Araujo 
O PRojeto de Lei de PRoteção de dAdos PEssoais (PL 5276/2016) NO MUNDO do Big DATA: O FENÔMENO DA DATAVEILLANCE EM RELAÇÃo À UTILIZAÇÃO DE METADADOS E SEU IMPACTO NOS DIREITOS HUMANOS ................................................................................... 185

Elias Jacob de Menezes Neto, Jose Luis Bolzan de Morais e Tiago José de Souza Lima Bezerra

DignidADE HUMANA NA WEBESFERA GOVERNAMENTAL BRASILEIRA...................................200 Luciana Cristina Souza

CiberespaÇo E CONTEÚdo OFENSIVO GERAdo POR TERCEIROS: A PROTEÇão DOS DiREITOS DE PERSONALIDADE E A RESPONSABILIZAÇÃo CIVIL DOS PROVEDORES DE APLICAÇÃO, À LUZ DA JURisprudênCIA do Superior Tribunal de JustiçA................................................ 217 Cristiano Colombo e Eugênio Facchini Neto

A responsabilidade CIVIL pelos atos autônomos da INTEligÊnCIA ARTIFICIAL: NOTAS iniciais sobre a resolução do Parlamento Europeu ...........................................239 Thatiane Cristina Fontão Pires

Rafael Peteffi da Silva

SHARENTING, LIBERDADE DE EXPRESSÃO E PRIVACIDADE DE CRIANÇAS NO AMBIENTE DIGITAL: O PAPEL DOS PROVEDORES DE APLICAÇÃo NO CENÁRIO JURÍDICO BRASILEIRO. 256 Fernando Büscher von Teschenhausen Eberlin

THE DICHOTOMY BETWEEN SMART METERING AND THE PROTECTION OF CONSUMER'S PERSONAL DATA IN BRAZILIAN LAW..

Lucas Noura Guimarães

O CYBERBULlying E OS LIMITES DA LIBERDADE DE EXPRESSÃO 295 Janile Lima Viana, Cinthia Meneses Maia e Paulo Germano Barrozo de Albuquerque

O Supremo Tribunal Federal e o discurso de ódio nas redes sociais: exercício de DIREITO VERSUS LIMITES À LIBERDADE DE EXPRESSÃO

Carlo José Napolitano e Tatiana Stroppa

ANÁlise COMPARAdA DE ESTRATÉgIAS DE ENFRENTAMENTO A “REVENGE PORN” PELO MUNDO .... 334 Natália Neris, Juliana Pacetta Ruiz e Mariana Giorgetti Valente

USO INDEVIDO DE REDES SOCIAIS E APLICATIVOS DE MENSAGENS INSTANTÂNEAS NO AMBIENTE LABORAL 
ENSAIO SOBRE A PROMESSA JURÍDICA DO ESQUECIMENTO: UMA ANÁLISE A PARTIR DA PERSPECTIVA DO PODER SIMBÓliCo DE BOURDIEU 368 Joana Machado e Sergio Negri

UMA AGENDA PARA O DIREITO AO ESQUECIMENTO NO BRASIL. 384 Bruno de Lima Acioli e Marcos Augusto de Albuquerque Ehrhardt Júnior

NÃo AdIANTA NEM TENTAR ESQUECER: UM ESTUdo SOBRE O DIREITO AO ESQUECIMENTO...... 412 José Augusto Fontoura Costa e Geraldo Miniuci

A aplicaÇão do direito ao ESQUecimento aos agentes delitivos: uma ANÁlise aCERCA da PONDERAÇÃO ENTRE O DIREITO À IMAGEM E AS LIBERDADES DE EXPRESSÃO E DE INFORMAÇÃO437 Paulo Afonso Cavichioli Carmona e Flávia Nunes de Carvalho Cavichioli Carmona

DiREITO AO ESQUECIMENTO: NA SOCIEDADE INFORMACIONAL HÁ ESPAÇO PARA O EPÍLOGO DA MÁQUINA DE TORTURA KAFKIANA?

Alexandre Antonio Bruno da Silva e Marlea Nobre da Costa Maciel

ESQUECIMENTO, INTERNET E “PREFERÊNCIA” DA INFORMAÇÃO: POSSIBILIDADES DE APLICAÇÃO DA DOUTRINA DOS PREFERRED RIGHTS DA JURISPRUDÊNCIA NORTE-AMERICANA AO CASO BRASILEIRO 484

Maria Vital da Rocha, Isaac Rodrigues Cunha e Karin de Fátima Rodrigues Oliveira

D. Propriedade intelectual 510

Direitos AUtorais E MÚSICA: TECNOLOGIA, DiREITO E REGUlaÇão Marcia Carla Pereira Ribeiro, Cinthia Obladen de Almendra Freitas e Rubia Carneiro Neves

Direito AUTORAL NA CIBERCUlTURA: UMA ANÁLISE Do ACESSO AOS BENS IMATERIAIS A PARTIR DAS LICENÇAS CREATIVE COMMONS 4.0.

Gabriela Maia Rebouças e Fernanda Oliveira Santos

E. Políticas públicas e novas tecnologias.

SALTO DIGITAL NAS POLÍTICAS PÚBLICAS: OPORTUNIDADES E DESAFIOS .561 Marcelo D. Varella, Clarice G. Oliveira e Frederico Moesch

Fostering E-gOVERnMENT IN BRAZIL: A CASE STUdY OF DIGITAL CERTIFICATION ADOPTION.585 Lamartine Vieira Braga

DEMOCRATIZAÇÃo NA ERA Digital: DESAFIOS PARA UM DiÁlOgo CONSCIENTE E IGUALITÁRIO.602 Raquel Cavalcanti Ramos Machado e Laura Nathalie Hernandez Rivera 
REDES SOCIAIS E CROWDSOURCING CONSTITUCIONAL: A INFLUÊNCIA DA CIBERDEMOCRACIA SOBRE A GÊNESE E A INTERPRETAÇÃO DE NORMAS CONSTITUCIONAIS ...................................... 618 Igor Ajouz

MARCo CIVIL DA INTERNET E POLÍTICA PÚbliCA DE TRANSPARÊNCIA: UMA ANÁLISE DA E-DEMOCRACIA E DO COMPLIANCE PÚBLICO.

Juliana Costa Zaganelli e Wallace Vieira de Miranda

Políticas públicas bRasileiras de COMPUTAÇÃo EM NUVEM: ANÁLISE DOCUMENTAL dos RELATÓRIOS DO GLOBAL CLOUD COMPUTING SCORECARD

Lucas dos Santos Costa e Marcos Fernando Machado de Medeiros

O uso monopolista do Big Data POR EMpresas de aplicativos: políticas públicas para UM DESENVOLVIMENTO SUSTENTÁVEL EM CIDADES INTELIGENTES EM UM CENÁRIO DE ECONOMIA CRIATIVA E DE LIVRE CONCORRÊNCIA...................................................................6 672 José Antonio Remedio e Marcelo Rodrigues da Silva

1. Introdução

2. A urbanização das cidades e a sociedade em rede: economia criativa, colaborativa e compartilhada como formas de concretização de funções sociais da cidade.

4. Concorrência e Big Data Business relevantes às Smart Cities: estudo de caso envolvendo a aquisição do Waze pelo Google

5. Considerações finais

Referências

III. OUTROS TEMAS

COMO SALVAR O SISTEMA DE REPERCUSSÃo GERAL: TRANSPARÊNCIA, EFICIÊNCIA E REALISMO NA escolha do Que o Supremo Tribunal Federal vai Julgar.. .696 Luís Roberto Barroso e Frederico Montedonio Rego

Precariedade do sistema penitenciário brasileiro como base temática para a proibição OU LEGALIZAÇÃO DAS DROGAS. 715

Lilian Rose Lemos Rocha e José Eduardo Cardozo

A terceira margem do constitucionalismo republicano: uma Crítica A Frank Michelman. .732

Daniel Barcelos Vargas

Medida PRovisória E CONTROLE DE CONSTITUCIONALIDADE: RELEVÂNCIA, URGÊNCIA E PERTINÊNCIA TEMÁTICA

Clarice G. Oliveira e José Levi Mello do Amaral Júnior 
ОвJETO E CONCEITO DO DIREITO ADMINISTRATIVO: REVISÃo CRÍTICA...................................765 Carlos Bastide Horbach

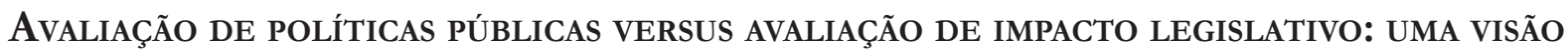
DICOTÔMICA DE UM FENÔMENO SINGULAR

Aparecida de Moura Andrade e Héctor Valverde Santana

LOS AVATARES DEL INTERÉS DEFINIDO EN TÉRMINOS DE PODER EN LA FORMULACIÓN DE LAS POLÍTICAS PÚBLICAS

Louis Valentin Mballa

CONSEQUENCIALISMO JUdicial NA MODUlaÇão DE EFEITOS DAS DECISÕES DECLARATÓRIAS DE INCONSTITUCIONALIDADE NOS JULGAMENTOS DE DIREITO TRIBUTÁRIO 819

Fernando Leal e Daniela Gueiros Dias

JudicializaÇão da SAÚde: A dignidade da PESSOA HuMana E A ATUAÇão do Supremo Tribunal Federal no caso dos medicamentos de alto custo

Fabricio Veiga Costa, Ivan Dias da Motta e Dalvaney Aparecida de Araújo 


\title{
O uso monopolista do Big Data por empresas de aplicativos: políticas públicas para um desenvolvimento sustentável em cidades inteligentes em um cenário de economia criativa e de livre concorrência*
}

\author{
The Big Data monopolistic use by technology \\ companies: public policies for sustainable \\ development in smart cities in a scenario of \\ creative economy and free competition
}

José Antonio Remedio**

Marcelo Rodrigues da Silva***

\section{Resumo}

* Recebido em 31/10/2017

Aprovado em 03/11/2017

** Doutor em Direito do Estado pela Pontifícia Universidade Católica de São Paulo (PUCSP). Professor de Graduação e Pós-graduação (Mestrado) em Direito da Universidade Metodista de Piracicaba (UNIMEP). Professor de Graduação em Direito do Centro Universitário Adventista de São Paulo (UNASP). Promotor de Justiça do Ministério Público do Estado de São Paulo Aposentado. Advogado. Email: jaremedio@yahoo.com.br

*** Mestrando em Direitos Fundamentais Coletivos e Difusos pela Universidade Metodista de Piracicaba - UNIMEP (bolsista CAPES/ PROSUP e CAPES/PROSUC). LL.M. em Direito Civil pela Universidade de São Paulo Faculdade de Direito de Ribeirão Preto (USP/ FDRP). Especialista em Direito Contratual pela Pontifícia Universidade Católica de São Paulo (PUCSP). Especialista em Direito Público pela Escola Paulista da Magistratura (EPM). Especialização em Direito Público pelo Damásio em convênio com a Universidade Potiguar. Colunista da Escola Superior de Direito Público (ESDP). Professor convidado da TV Justiça (Coordenada pelo Supremo Tribunal Federal STF). Professor convidado da pós-graduação em Criminologia, Direito Penal e Processo Penal da Pontifícia Universidade Católica de Campinas (PUC-CAMPINAS). Professor convidado da pós-graduação em Ciências Criminais na Rede de Ensino LFG/Anhanguera. Professor do Atualidades do Direito (Portal AD). Exrepresentante do IDESP.BRASIL. Advogado. Associado ao IBCCRIM, CONPEDI e BRASILCON. Email: marcelordsadv@gmail.com
O objetivo deste artigo é analisar o uso do Big Data por empresas de aplicativos, com ênfase às políticas públicas voltadas para um desenvolvimento sustentável, em cidades inteligentes, em um cenário de economia criativa. $\mathrm{O}$ método utilizado é o hipotético-dedutivo, com base em pesquisa doutrinária. Historicamente, a urbanização desordenada das cidades, com a saturação demográfica de seu espaço geográfico, tem acarretado inúmeros problemas urbanísticos aos indivíduos e à sociedade, como a instalação de habitações precárias, a implantação de transporte público inadequado e a ocorrência de ofensas ambientais das mais variadas ordens. O Big Data, na atualidade, possibilita o acompanhamento de comportamentos humanos em tempo real e de maneira massificada, proporcionando inteligência às cidades, quando devidamente processados e analisados os dados que o integram. A cidade inteligente, gerida por dados, é caracterizada pela capacidade dos gestores utilizarem tecnologias próprias para a geração, captação, processamento e análise de dados, visando, entre outros fins, ao desenvolvimento de áreas sociais, educacionais, econômicas e ecológicas em relação ao ambiente urbano. Conclui-se que o uso do Big Data, com a integração da sociedade em rede, possibilita a implementação de uma economia criativa, colaborativa e compartilhada, permitindo a ampliação e concretização de diversas funções sociais da cidade, em especial por meio da implementação de políticas públicas pelos gestores públicos, voltadas para a transformação e prestação dos serviços públicos, por meio da adequada gestão do meio ambiente urbano, contribuindo, assim, para o desenvolvimento urbano sustentável e para a cidade mais humanizada.

Palavras-chaves: Big Data. Cidades inteligentes. Desenvolvimento sustentável. Economia criativa. Empresas de tecnologia. Processo Coletivo. 


\section{Abstract}

The purpose of this paper is the use of Big Data by software companies, with emphasis on public policies geared towards sustainable development, smart cities, and a creative economic scenario. The method used is the hypothetical-deductive, based on doctrinal research. Historically, the disorderly urbanization of cities, with a demographic saturation of its geographic space, has led to innumerable urban problems to its people and society, such as precarious housing, insufficient public transportation and the occurrence of a variety of environmental offenses. Today, Big Data enables the monitoring of human behaviors in real time, providing intelligence to the cities when properly processed and analyzed. The intelligent, data-driven city, is characterized by the ability of its managers to use their technology for generation, capture, processing and data analysis, aiming to develop social, education, economic and ecological areas in relation to the urban environment. In conclusion, the use of Big Data, with a network integrated society, allows the implementation of a creative, collaborative and shared economy, allowing the widening and concretization of several public functions, specially through public policies by public managers, aimed to the transformation and provision of public services, through a good urban environment management and contributing to a sustainable urban development and a more humanized city.

Keywords: Big Data. Smart cities. Sustainable development. Creative economy. Technology companies. Collective process.

\section{INTRODUÇÃO}

A urbanização desordenada das cidades, fenômeno que ocorre há várias décadas, com a saturação demográfica de seu espaço geográfico, tem provocado inúmeras dificuldades e transtornos aos indivíduos e à sociedade, como a instalação de habitações precárias, a implantação de transporte público inadequado, a precariedade na prestação dos serviços públicos essenciais, a ineficiência da segurança pública, o crescimento da poluição ambiental e a ampliação do desemprego.

O crescimento horizontal desordenado, com a proliferação de aglomerações, metropolizações e macrocefalias urbanas, desqualifica o espaço geográfico das cidades, dando ensejo à saturação do referido espaço, gerando, por conseguinte, problemas urbanos das mais variadas ordens.

A precariedade da gestão pública, em relação à aplicação dos recursos públicos, também contribui para a ampliação do problema urbano, seja em face da inabilidade do gestor, dando ensejo ao desperdício dos recursos, seja em razão da má-fé do gestor, por meio de desvio de recursos públicos em seu favor ou de terceiros.

O século XXI, dando ensejo ao nascimento da Era da Informação, apresenta o surgimento de uma "sociedade em rede", na qual os avanços da tecnologia da informação e comunicação geram importantes reflexos sociais, inclusive em relação às cidades. ${ }^{1}$

Nesse contexto surge o Big Data, que possibilita o acompanhamento de comportamentos humanos em tempo real e de maneira massificada, proporcionando inteligência às cidades, quando devidamente processados e analisados os dados que o integram.

A cidade inteligente, gerida por dados, é caracterizada pela capacidade de os gestores utilizarem tecnologias próprias para a geração, captação, processamento e análise de dados, objetivando, entre outros fins, o desenvolvimento de áreas sociais, educacionais, econômicas e ecológicas em relação ao ambiente urbano.

1 CASTELLS, Manuel. Sociedade em rede: a era da informação: economia, sociedade e cultura. São Paulo: Paz e Terra. 1999. v.1. p. 488. 
O processo coletivo, como instrumento judicial de implementação dos direitos difusos e coletivos, constitui um dos efetivos instrumentos a possibilitar a concretização do objeto das Smart Cities.

Estruturalmente, a pesquisa é dividida em três partes: a primeira analisa a urbanização das cidades e a sociedade em rede, com ênfase à economia criativa, colaborativa e compartilhada como formas de concretização de funções sociais da cidade; a segunda enfoca as Smart Cities e sua relação com as políticas públicas guiadas a partir do Big Data (data driven cities); a última aborda a concorrência e Big Data Business relevantes às Smart Cities, com o estudo de caso envolvendo a aquisição do Waze pelo Google.

A pesquisa, valendo-se do método hipotético-dedutivo, tem como objetivo analisar o uso do Big Data por empresas de aplicativos, com ênfase às políticas públicas voltadas para um desenvolvimento sustentável, em cidades inteligentes, em um cenário de economia criativa.

Tem-se, como hipótese, que o Big Data, integrando a sociedade em rede e colaborando para o surgimento da cidade inteligente, possibilita a implementação de uma economia criativa, colaborativa, compartilhada e de livre concorrência, permitindo a ampliação e a concretização de diversas funções sociais da cidade, em especial por meio da implementação de políticas públicas pelos gestores públicos, voltadas para a transformação e a prestação dos serviços públicos, contribuindo, assim, para o desenvolvimento urbano sustentável e para uma cidade mais humanizada.

\section{A URBANIZAÇÃo dAs CIDADES E A SOCIEDADE EM REDE: ECONOMIA CRIATIVA, COLABORATIVA E COMPARTILHADA COMO FORMAS DE CONCRETIZAÇÃO DE FUNÇÕES SOCIAIS DA CIDADE}

A transição abrupta, no Brasil, do modelo econômico agrário-exportador para o industrial, a partir da década de 1930, tornou as zonas urbanas mais atrativas em razão da expectativa pela oferta de empregos na indústria e no comércio, avanços nas áreas de transportes, iluminação urbana e outros relacionados à infraestrutura, impulsionando, assim, o êxodo rural e a consequente urbanização vertiginosa, irracional e desordenada de algumas regiões do território brasileiro.

Em 2010, conforme apontou o Censo Demográfico do Instituto Brasileiro de Geografia e Estatística - IBGE ${ }^{2}$ do mesmo ano, a população brasileira que vivia nas cidades era de $84,36 \%$, o que representava 160.925.792 de pessoas, e esse percentual tendia a aumentar.

Ao revés do que ocorreu em países desenvolvidos, a oferta de empregos urbanos não atendeu o fluxo migratório, gerando déficit habitacional e assentamentos urbanos informais densamente povoados, caracterizados por moradias precárias e miséria, a exemplo das favelas ${ }^{3}$. De outro lado, aqueles que conseguiram empregos na indústria (a massa trabalhadora), fixaram-se nas periferias das cidades, normalmente em parcelamentos do solo ou loteamentos urbanos de baixo custo, nos quais era facilitada a aquisição dos lotes ou terrenos pela população migratória.

A compreensão ultrapassada de desenvolvimento como sinônimo de crescimento econômico ${ }^{4}$, medido unicamente pelo produto interno bruto (PIB) ${ }^{5}$, gerou reflexos negativos nas políticas públicas dos anos 70, que, de acordo com Marcelo Dias Varella, levaram à ideia de ser necessário primeiramente acumula-

2 INSTITUTO BRASILEIRO DE GEOGRAFIA E ESTATÍSTICA (IBGE). Censo Demográfico 2010. Disponível em: <https:// censo2010.ibge.gov.br/sinopse/index.php?dados=11\&uf=00>. Acesso em: 27 out. 2017.

3 CAMPOS FILHO, Cândido Malta. Cidades brasileiras: seu controle ou caos: o que os cidadãos devem fazer para a humanização das cidades no Brasil. São Paulo: Studio Nobel, 1999. p. 30.

4 Segundo Amartya Sen, não se pode medir desenvolvimento com o crescimento econômico, pois justamente esconde a desigualdade social. SEN, Amartya. Desenvolvimento como liberdade. Rio de janeiro: Companhia de Bolso, 2010.

5 PIB é a sigla para Produto Interno Bruto e representa a soma, em valores monetários, de todos os bens e serviços finais produzidos numa determinada região, durante um determinado período. 
ção individual de capital, para, posteriormente, implementar políticas públicas sociais para inserção dos mais pobres ${ }^{6}$. Esse modelo de gestão econômica gerou a concentração de esforços governamentais em setores prioritários, principalmente a Indústria. Assim, "a infraestrutura urbana, igualmente, alinhou-se a esta lógica clientelista de concessão de privilégios aos setores industriais e às classes sociais abastadas" concentrando a "aplicação de recursos para a urbanização de bairros que já tinham equipamentos públicos básicos, fomentando-se o adensamento populacional destas zonas e a abreviação da suficiência das instalações implantadas". ${ }^{8}$

Houve, segundo Andrea Teichmann Vizzotto, a divisão territorial das cidades conforme as classes sociais $^{9}$. Aglomerações urbanas ${ }^{10}$, metropolizações ${ }^{11}$ e macrocefalias urbanas ${ }^{12}$ são expressões do crescimento horizontal desqualificado do espaço geográfico urbano, e resultaram em saturação do referido espaço, dificultando a absorção pelas cidades, nas searas econômica e geográfica, dos quantitativos populacionais existentes, gerando habitações precárias e irregulares (ou mesmo ausência destas ${ }^{13}$ ), mobilidade urbana deficiente, segurança pública ineficiente, transportes públicos inaptos, saneamento básico inadequado, problemas ambientais etc.

A elevada densidade populacional urbana, somada à baixa performance ou inabilidade do gestor público, ocasiona alocação inadequada de recursos públicos (ausência de qualidade dos gastos públicos), culminando no desperdício passivo (v.g.: obras inacabadas, investimentos desnecessários, morosidade de atuação etc.). O problema agrava-se com quadros de má-fé (improbidade administrativa) do gestor público, a exemplo do que ocorre com a corrupção administrativa (desperdício ativo).

A título de exemplo, conforme informação de Débora Brito, citada por José Antonio Remedio, em balanço divulgado em dezembro de 2016, referente à operação Lava Jato, constatou-se que em 2016 foram iniciadas 17 investigações e apresentadas 20 denúncias por crimes de corrupção ativa e passiva, lavagem de dinheiro e organização criminosa; cerca de $\mathrm{R} \$ 500$ milhões foram devolvidos à Petrobrás desde o início da operação; o valor das propinas pagas supera $\mathrm{R} \$ 6,4$ bilhões; o total dos prejuízos poderá ultrapassar $\mathrm{R} \$ 40$

6 VARELLA, Rodrigo Dias. Evolução do conceito de desenvolvimento: do crescimento econômico a expansão das liberdades. 12 de dezembro de 2011. Disponível em: < https://www.youtube.com/watch?time_continue=2899\&v=C7E_1aMPE-E>. Acesso em: 29 out. 2017.

7 HUNGARO, Luis Alberto. Parceria público-privada municipal: a concretização de funções sociais da cidade: habitação, saneamento básico e mobilidade urbana. Rio de Janeiro: Lumen Juris, 2017. p. 13.

8 HUNGARO, Luis Alberto. Parceria público-privada municipal: a concretização de funções sociais da cidade: habitação, saneamento básico e mobilidade urbana. Rio de Janeiro: Lumen Juris, 2017. p. 13.

9 VIZZOTTO, Andrea Teichmann. A recuperação de mais-valias urbanas e os eventos esportivos. In: ALFONSIN, Betânia Moraes; PAGANI, Elaine Adelina; SOMENSI, Simone (Org.) Congresso Comemorativo aos 30 anos do Estatuto da Cidade - II Congresso de Direito Urbano-Ambiental. Porto Alegre: Fundação Escola Superior de Direito Municipal, 2011. p. 96.

10 Conforme artigo $2^{\circ}$, inciso I do Estatuto da Metrópole (Lei n ${ }^{\circ}$ 13.089/2015), considera-se aglomeração urbana a "unidade territorial urbana constituída pelo agrupamento de 2 (dois) ou mais Municípios limítrofes, caracterizada por complementaridade funcional e integração das dinâmicas geográficas, ambientais, políticas e socioeconômicas”. BRASIL. Lei n ${ }^{\circ} 13.089$, de 12 de janeiro de 2015. Disponível em: <http://www.planalto.gov.br/ccivil_03/_ato2015-2018/2015/lei/113089.htm>. Acesso em: 29 out. 2017. 11 A metropolização consiste no processo de crescimento urbano de uma cidade e sua constituição como centralidade de uma região metropolitana, isto é, de uma área composta por vários municípios que congregam a mesma dinâmica espaço-territorial. A metrópole passa a ser vista como a zona na qual as demais cidades tornam-se dependentes e interligadas economicamente. Entre os exemplos de metrópoles no Brasil, tem-se as cidades de São Paulo, Rio de Janeiro, Belo Horizonte, Salvador, Goiânia, Porto Alegre e muitas outras.

12 A macrocefalia urbana é caracterizada pela demasiada concentração de atividades econômicas, equipamentos urbanos, oferta de serviços e população em uma limitada espacialidade. Grandes centros urbanos de países periféricos e semiperiféricos consistem na perfeita manifestação da macrocefalia urbana, a exemplo do que ocorre no Brasil, país que possui cerca de 5.574 cidades, porém 22 delas tão somente concentram funções econômicas, culturais, políticas, administrativas, deixando as demais cidades dependentes de tudo que acontece nessas 22. A macrocefalia urbana é uma consequência do processo de desqualificação da urbanização, pois na medida em que a população se transfere do campo para as cidades de maneira acelerada, desorganizada e descapitalizada, não há tempo de se implantar uma infraestrutura urbana bem distribuída, gerando a intensa concentração que manifesta a macrocefalia. 13 O Censo 2010 aferiu a demanda de 6,490 milhões de moradias, o que correspondia a 12,1\% dos domicílios do país. INSTITUTO BRASILEIRO DE GEOGRAFIA E ESTATÍSTICA - IBGE. Censo Demográfico 2010. Disponível em: <https://censo2010. ibge.gov.br/sinopse/index.php?dados=11\&uf=00>. Acesso em: 27 out. 2017. 
bilhões; houve 120 condenações penais e mais de 1.200 anos de pena foram aplicados aos infratores na esfera criminal. ${ }^{14}$

No século XXI (Era de Informação), testemunha-se um momento de ruptura com a "sociedade industrial", com o nascimento de uma "sociedade em rede" (terminologia adotada por Manuel Castells ${ }^{15}$ ), em que os avanços da tecnologia da informação e comunicação geram importantes reflexos sociais, inclusive no que tange às cidades. De acordo com Manuel Castells, "a era da informação está introduzindo uma nova forma urbana, a cidade informacional"16, em que há uma potencialização da interação pela via de um "canal horizontal de comunicação"17 entre administrados e Administração Pública. Segundo Yoachai Benkler, as redes permitem que todos os cidadãos mudem suas relações com a esfera pública. Nas palavras do autor: "Eles já não precisam ser consumidores e espectadores passivos. Podem se tornar criadores dos principais temas. É neste sentido que a internet democratiza" ${ }^{\prime 18}$.

Nos dizeres de Milton Santos, "as cidades têm um grande papel na criação de fermentos que conduzem a ampliar o grau de consciência. Por isso são um espaço de revelação"19.

As cidades, hoje, estão diretamente ligadas ao exercício da cidadania. Todavia, a cidadania não se resume tão somente à condição de cidadão estático, condicionado e limitado à fruição de direitos, mas também está atrelada à condição de ator responsável pela implementação de projetos de cunho social, cultural, tecnológi$\mathrm{co}$, medicinal, mercadológico, etc. ${ }^{20}$, favorecendo, assim, a geração de riquezas, progresso e desenvolvimento, meios esses de instrumentalização dos cidadãos colaboradores para o efetivo exercício da cidadania ${ }^{21}$.

Acompanhando o pensamento de Manuel Castells, pode-se afirmar que o atual momento histórico se relaciona a uma estrutura econômica de capitalismo informacional, em que capital, trabalho e a forma de produção e consumo são alteradas "tendo-se como base o manejo de informações para o desenvolvimento. Informações que podem levar a uma maior inovação tecnológica, à difusão do conhecimento, ao aprimoramento das instituições democráticas com transparências e interatividade entre cidadão e governo, dentre

14 REMEDIO, José Antonio; BUONAMICI, Sérgio Claro. Corrupção administrativa: histórico, efeitos danosos e combate por meio de instrumentos de tutela coletiva. Revista Paradigma, Ribeirão Preto, v. 26, p. 152, 2017.

15 CASTELLS, Manuel. Sociedade em rede: a era da informação: economia, sociedade e cultura. São Paulo: Paz e Terra. 1999. v. 1. p. 488.

16 CASTELLS, Manuel. Sociedade em rede: a era da informação: economia, sociedade e cultura. São Paulo: Paz e Terra. 1999. v. 1. p. 488.

17 CASTELLS, Manuel. A galáxia da internet: reflexões sobre a internet, os negócios e a sociedade. Tradução: Maria Luiza X. de A. Borges. Rio de janeiro, 2003. p. 129.

18 BENKLER, Yochai. The wealth of networks: how social production transforms markets and freedom. New Heaven: Yale University Press, 2006. p. 271-272. No mesmo sentido: “Accessible, well-visualized data is ending government's monopoly on information and authority. An important part of the digital revolution in governance will be the use of those tools by ordinary people to engage their government in ways that were unimaginable only a few years ago. We think that engagement will create a new kind of civic life in which government and its citizens will work as true partners to solve urban problems. That in turn will encourage people to see themselves as active citizens rather than passive consumers of services". CRAWDFORD, Susan; GOLDSMITH, Stephen. The responsive city: engaging communities through data-smart governance. San Francisco: Jossey-Bass, 2014. p. 56.

19 SANTOS, Milton. O espaço do cidadão. São Paulo: EDUSP, 2014. v. 8. p. 83-84.

20 "Ainda que se possa considerar que o Estado tem o dever de buscar soluções criativas para melhoria da gestão pública e dos serviços oferecidos à sociedade, deve-se reconhecer que este é um desafio que pode estar além da sua capacidade, seja por limitações tecnológicas, orçamentárias ou culturais. Ademais, aplica-se também ao Poder Público a afirmativa de Chesbroug: 'Não se pode assumir que todas as pessoas inteligentes trabalham para nós, então devemos encontrar e aproveitar o conhecimento e a experiência de indivíduos brilhantes fora da nossa organização' [...] Pode-se dizer que essa abordagem representa um passo além na abertura à participação e no compartilhamento de responsabilidades entre governo e cidadão, no sentido de que a colaboração entre pessoas engajadas em causas sociais, pesquisadores e organizações não governamentais resulta na implementação efetiva de serviços inovadores de interesse público, e não apenas em ideias" COSTA, Gledson Pompeu da. Inovação: dever do Estado, direito do cidadão. In: OLIVEIRA, Aroldo Cedraz de (Coord.). O controle da Administração na era digital. Belo Horizonte: Forum, 2016. p. 131.

21 SILVA, Marcelo Rodrigues da. Os excessos arrecadatórios nos Crowdfundings doação e recompensa: enriquecimento sem causa? 2017. TCC (Monografia) - Universidade de São Paulo, São Paulo, 2017. p. 21. 
outros" 22 . Portanto, no capitalismo informacional, "a inteligência é seu maior patrimônio"23, tendo a "inovação e a flexibilidade como características essenciais do novo sistema de produção"24.

Sob a ótica dos diferentes padrões de desempenho de papeis na produção e consumo, identificam-se três eras sociais: a forma de produção anterior ao período industrial é identificada como uma sociedade focada na autossuficiência, ou seja, cada produtor, também, era um consumidor de seus produtos (primeira era); com a Revolução Industrial, surge a produção de mercado de massa (segunda era); a terceira era (Sociedade da Informação) leva o mercado a perder o seu domínio, e o consumidor ${ }^{25}$ passa a fazer parte do processo de produção ${ }^{26}$.

De acordo com José Francisco Siqueira Neto e Daniel Francisco Nagao Menezes, a "desmaterialização das relações de trabalho e de formação de uma economia baseada na informação e conhecimento" fez surgir a economia criativa, cujo novo paradigma inclui aparatos culturais e tecnológicos como instrumentos de "propulsão, a organização dos mercados em redes, alianças entre agentes econômicos e sociais, a prevalência de aspectos intangíveis de produção, distribuição e/ou acesso a bens e serviços e a singularidade de produção", com laços fortemente atrelados à singularidade, "são características deste modelo que é suposto sustentabilidade melhorar o bem-estar e a inclusão socioeconômica, superando assim o chamado 'paradigma da chaminé"'27.

Patricia Peck Pinheiro diz que esse poder de colaboração em massa denomina-se wikinomics, que é "um novo modelo de infraestrutura típico de geração de conhecimento de baixo custo, em que pessoas e empresas colaboram de forma 'aberta' para impulsionar a inovação"28. Acrescenta a autora que "a tecnologia da informação permite que milhões de pessoas unam forças em colaborações auto-organizadas, que produzem novos bens e serviços dinâmicos e que rivalizam com os das maiores empresas. A isso hoje se define como peer production" 29 .

Nos dizeres de Cristian Iosio e Giorgio Valentinuz, em um cenário de economia colaborativa, dá-se "ênfase ainda maior sobre as pessoas e sua rede — construída ao longo do tempo por meio do compartilhamento de paixões, interesses, opiniões etc. — que representa o verdadeiro valor e patrimônio" 30 . As comunidades, segundo os autores, tornaram-se motores do crescimento.

Os cidadãos, conectados em redes e pela tecnologia, podem, em uma atividade criativa, colaborar uns com os outros e, também, diretamente com o governo para melhorar a vida das cidades (co-governance, co-

22 LONGHI, João Victor Rozatti. Processo legislativo interativo: interatividade e participação por meio das tecnologias da informação e comunicação. Curitiba: Juruá, 2017. p. 78.

23 CASTELLS, Manuel. Fim do milênio: a era da informação: economia, sociedade e cultura. São Paulo: Paz e Terra. 1999. v. 3. p. 418.

24 CASTELLS, Manuel. Fim do milênio: a era da informação: economia, sociedade e cultura. São Paulo: Paz e Terra. 1999. v. 3. p. 418.

25 Deve-se captar de a acepção "consumidor" não em seu sentido técnico de produção e consumo, mas sim o sentido dos cidadãos usufruírem benefícios de suas condutas ativas.

26 "Der amerikanische Zukunftsforscher Alvin Toffler (1983) definiert in seinem Buch The Third Wave den Übergang von der Industrie- zur Informationsgesellschaft als dritte Welle der gesellschaftlichen Entwicklung. Toffler identifiziert anhand der unterschiedlichen Muster der Rollenübernahme in der Produktion und Konsumation drei gesellschaftliche Zeitepochen: In der vor - und frübindustriellen Zeit war Produktion ursprïnglich immer auf Selbstversorgung gerichtet. Jeder Produzent war zugleich Konsument seiner Produkte (erste Welle). Die Industrielle Revolution trennte die beiden Tätigkeitsprofile: Massenmarktproduktion stand im Vordergrund (zweite Welle: Zeitalter der Industrialisierung). Die dritte Welle fübrt in die sogenannte, "TransmarktGesellschaft", in der der Markt seine Dominanz verliert. Der Konsument wird Teil des Produktionsprozesses". SIXT, Elfriede. Schwarmokonomie und crowdfunding: webasierte finanzierungssysteme im rahmen realwirschaftlicher bedingungen. Bisamberg: Elfriede Sixt, 2014 . p. 11. (Tradução livre).

27 MENEZES, Daniel Francisco Nagao; SIQUEIRA NETO, José Francisco. Ensaios de economia criativa e colaborativa e sua regulação. Belo Horizonte: Arraes Editores, 2017. p. 65.

28 PINHEIRO, Patricia Peck. Direito digital. 6. ed. São Paulo: Saraiva, 2016. p. 447.

29 PINHEIRO, Patricia Peck. Direito digital. 6. ed. São Paulo: Saraiva, 2016. p. 447-448.

30 "pone un accento ancor maggiore sulle persone e sul loro network - costruito nel tempo attraverso la condivisione di passioni, interessi, opinioni ecc. - che rappresenta il vero valore e patrimônio" IOSIO, Cristian; VALENTINUZ, Giorgio. Fare impresa com il crowdfunding. Cidade: Wolter Kluwer, 2016. p. 11. (Tradução livre). 
-design e co-production), e juntos podem aperfeiçoar e gerar novos serviços públicos. Há necessidade de empoderamento tecnológico e digital dos indivíduos para que participem do processo de transformação ( $v . g .:$ wi-fi público de qualidade).

Deve-se estimular outros modelos, já que muitas das estruturas vigentes não atendem mais às formas como se hoje se relacionam com a sociedade. Existem sinais emergentes de soluções na sociedade. E, portanto, é preciso aproveitar esse capital social, coordenar essas soluções e promovê-las.

Cidadãos, startups e empresas em geral são importantes players da sociedade em rede, pois podem, por meio da criação (economia criativa) de aplicativos e tecnologia, trazer melhorias às cidades e desenvolver ativos intangíveis aos seus produtos (v.g.: "propriedade intelectual, capital organizacional, conteúdos gerados pelo usuário e capital humano" - "que também compõe uma fatia crescente dos ativos capitais da economia” ${ }^{31}$, mas lamentavelmente são ignorados pelo PIB - Produto Interno Bruto - oficial ${ }^{32}$ ) e com isso gerar lucro. Assim, ocorre, por exemplo, com o aplicativo Waze, que, por meio do sistema de georreferenciamento dos smartphones de todos os seus usuários, traz melhorarias ao sistema viário e o escoamento do tráfego (fornecendo rotas com caminhos menos congestionados, indicação de acidentes etc.). Inclusive, a Companhia de Engenharia de Tráfego (CET) de São Paulo formalizou no dia 20 de setembro de 2017 uma parceria com o referido aplicativo para viabilizar o acionamento de agentes para reparar semáforos e desbloquear o trânsito pelo aplicativo, tornando tais serviços públicos mais eficientes ${ }^{33}$. Ou seja, constroem-se políticas públicas com base em inteligência coletiva (fomentada por informações sobre o trânsito pela rede de usuários do aplicativo). Entre outros, podem-se citar os seguintes aplicativos que acabaram impactando as cidades: Uber $^{34}$, Airbnb ${ }^{35}$, Moovit ${ }^{36}$, Moovit Carpool Carona Compartilhada ${ }^{37}$, Cadê o Ônibus ${ }^{38}$, BlablaCar ${ }^{39}$, iFood ${ }^{40}$, Colab.re ${ }^{41}$, plataformas de financiamento coletivo (crowdfunding) ${ }^{42}$. Tais aplicativos, estruturados em economias de compartilhamento (sharing economy), valem-se de dados (ou valores - no caso do crowdfunding) for-

31 BRYNJOLFSSON, Erik; McAFEE, Andrew. A segunda era das máquinas: trabalho, progresso e prosperidade em uma época de tecnologias brilhantes. Rio de Janeiro: Alta Books, 2015. p. 134.

32 BRYNJOLFSSON, Erik; McAFEE, Andrew. A segunda era das máquinas: trabalho, progresso e prosperidade em uma época de tecnologias brilhantes. Rio de Janeiro: Alta Books, 2015. p. 136.

33 MOREIRA, Marli. Prefeitura de SP fazparceria com aplicativo do Waze para melhorar o trânsito. 20 de setembro de 2017. Disponível em: <http://agenciabrasil.ebc.com.br/geral/noticia/2017-09/prefeitura-de-sp-faz-parceria-com-aplicativo-waze-para-melhorar-otransito>. Acesso em: 29 out. 2017.

34 O Uber toma por conceito e-healing, que permite solicitar uma carona remunerada, conectando motoristas e passageiros de maneira simplificada e rápida. A plataforma virtual vale-se também da tecnologia de localização, que autoriza o usuário a acompanhar todo o percurso realizado pelo motorista do carro contratado.

35 Airbnb é uma plataforma online comunitária para as pessoas anunciarem, buscarem e reservarem acomodações e meios de hospedagem.

36 O Moovit trata-se de aplicativo ligado ao transporte público. Ele combina todas as opções de transporte público (metrô, ônibus e trens) em sua plataforma, realizando constantes atualizações de seus bancos de dados a fim de informar os horários cedidos pelas operadoras de trânsito, evitando que o usuário fique esperando em um ponto desativado ou por um ônibus que alterou sua rota. Ademais, o referido aplicativo permite o controle total das viagens pelo usuário, garantindo-lhe maior tranquilidade.

37 O Moovit Carpool combina passageiros e motoristas que estão seguindo numa mesma direção a fim de oferecer ou pegar caronas.

38 O Cadê o Ônibus é um aplicativo em que permite ver em tempo real onde os ônibus encontram-se.

39 O BlablaCar trata-se de aplicativo de caronas entre cidades.

40 O iFood permite pedir refeições de lanchonetes ou restaurantes próximos diretamente pelo celular, sem precisar gastar créditos com ligações. O aplicativo avisa quando o pedido foi recebido, quando está em preparação e quando sai para entrega, também permite os usuários avaliarem os estabelecimentos quanto à qualidade da comida, entrega e atendimento.

41 O aplicativo Colab.re tem por objetivo fiscalizar a qualidade de serviços públicos e incentivar a tomada de decisões do governo com base na participação popular por meio do referido aplicativo.

42 De acordo com Cristiano Chaves de Faria, Felipe Braga Netto e Nelson Rosenval, o crowdfunding é "um modo de arrecadar, virtualmente, fundos para determinado projeto que o usuário propõe”. FARIAS, Cristiano Chaves de; BRAGA NETTO, Felipe; ROSENVALD, Nelson. Novo tratado de responsabilidade civil. 2. ed. São Paulo: Saraiva, 2017. p. 786. Tem importância salutar para as cidades, na medida em que viabiliza projetos sociais, culturais, medicinais, científicos e tecnológicos importantes, como, por exemplo, o caso da campanha "Por uma cidade para todos" realizada na plataforma de crowdfunding Benfeitoria, em que se busca arrecadar valores para viabilizar a construção de casas de emergência e projetos comunitários ao longo de 2017 com moradores das favelas (https://benfeitoria.com/galenca). 
talecidos por usuários diversos, potenciais consumidores, e outros fluxos informacionais, e fazem conexão desses usuários por intermédio de uma plataforma virtual, sendo que o funcionamento destes aplicativos tem por base a confiança ${ }^{43}$, que é criada por meio de um sistema de reputação objetiva (track record) fomentado por avaliações em todas as oportunidades em que o serviço for tomado.

Os impactos provocados pela tecnologia no "mundo real" são denominados por Steve Case como terceira onda da internet ${ }^{44}$, na qual ver-se-á uma grande mudança nos negócios e o renascimento do empreendedorismo. A primeira onda diz respeito à criação de base para que consumidores começassem a se conectar e utilizar a internet, inicialmente apenas no ambiente profissional. $\mathrm{Na}$ segunda onda, companhias como Google e Facebook lançaram as redes sociais, e hoje vive-se o tempo todo conectados ao Instagram e ao Snapchat - o que antes estava apenas no âmbito do trabalho invadiu nosso dia a dia por completo. Segundo o autor, agora está-se entrando em uma nova fase: a terceira onda, momento em que empreendedores utilizarão a tecnologia para revolucionar o "mundo real".

A dinâmica social em rede protagonizada pela "terceira onda da internet" (Steve Case) alterou o modelo econômico, mas as estruturas governamentais continuam moldadas na era industrial. Assim, há necessidade de remodelar algumas práticas que continuam atreladas a modelos puramente burocráticos e ineficientes do Poder Público, bem como adotar modelos regulatórios que atendam a nova dinâmica social, baseada no modelo democrático-participativo e em redes (descentralização do serviços públicos), viabilizando a inovação ${ }^{45}$ e o surgimento de novas tecnologias (artigo 218 e seguintes da Constituição Federal de 1988) para melhor cumprir as funções sociais da cidade (artigo 182 da Constituição Federal de 1988 e artigo $2^{\circ}$ e incisos do Estatuto da Cidade).

A inovação trata-se valor jurídico fundamental das atividades relativas ao Poder Público, devendo os seus agentes públicos atuarem de forma a viabilizá-la e permiti-la.

Muito embora existam óbices normativos à inovação ${ }^{46}$ no âmbito da Administração Pública, Carlos Ari Sundfeld diz que é possível a inovação, adotando a Administração Pública, para tanto, pelo menos quatro soluções a fim de compatibilizar a legalidade Administrativa com a necessidade de inovação, quais sejam: (i) "intepretações atualizadoras e flexibilizadoras"47; (ii) leis-quadro, havendo neste caso a necessidade de intervenção do legislador construindo uma lei de standards, de competências, de normas sobre processo que permitam que a Administração Pública confeccione a regulação de maneira ágil a fim de acompanhar as constantes mutações tecnológicas. Esta solução é mais difícil de concretização em um ambiente democrático, pois se anseia a participação do Poder Legislativo; (iii) Regime legal excepcional (bypass) ou inovações pontuais ( $v . g .:$ pregão eletrônico, que foi ampliando paulatinamente por via legislativa o seu âmbito de incidência); (iv) ilegalidade, em especial quando se sobressaem aspectos sociais favoráveis que amparem a legalização da inovação ${ }^{48}$.

43 Sobre confiança nas economias do compartilhamento ver: CARVALHO, Vinicius Marques de; MATTIUZZO, Marcela. Confiança, reputação e redes: uma nova lógica econômica? In: KIRA, Beatriz; PAULA, Pedro C. B. De Paula; ZANATTA, Rafael A. F (Org.). Economias do compartilhamento. Curitiba: Juruá, 2017. p. 41- 57; LEMOS, Ronaldo; SOUZA, Carlos Affonso Pereira de. Aspectos jurídicos da economia do compartilhamento: função social e tutela da confiança. In: KIRA, Beatriz; PAULA, Pedro C. B. De Paula; ZANATTA, Rafael A.F (Org.). Economias do compartilhamento. Curitiba: Juruá, 2017. p. 59-77.

44 CASE, Steve. A Terceira onda da internet: como reinventar os negócios na era digital. São Paulo: HSM, 2017. (livro digital).

45 O artigo $4^{\circ}$ da Lei número 12.965, de 23 de abril 2014 reza que "a disciplina do uso da internet no Brasil tem por objetivo a promoção: [...] III - da inovação e do fomento à ampla difusão de novas tecnologias e modelos de uso e acesso".

46 HOFFMANN-RIEM, Wolfgang. Direito, tecnologia e inovação. In: MENDES, Gilmar Ferreira; SARLET, Ingo Wolfgang; COELHO, Alexandre Zavaglia P. Direito, inovação e tecnologia. São Paulo: Saraiva, 2015. v. 1. p. 15.

47 Carlos Ari Sundfeld cita como exemplo de interpretação atualizadora ou flexibilizadora a proibição de realização de acordos na lei de improbidade administrativa, que, nada obstante, o Ministério Público faz acordos de leniência com efeitos nas ações de improbidade- houve uma reinterpretação do ordenamento jurídico. Diz o referido autor que há muita insegurança jurídica com relação as interpretações atualizadoras, pois inexistem mecanismos ineficientes para firmar interpretação que tenha validade para todos os âmbitos, inclusive os âmbitos controladores. SUNDFELD, Carlos Ari. Como compatibilizar legalidade administrativa e inovação?. 2017. Rio de Janeiro: UERJ Reg. 2017. Disponível em: <https://www.facebook.com/uerjreg/videos/2066124990273034/>. Acesso em: 11 de janeiro de 2018).

48 A ilegalidade, embora seja um mecanismo de inovação, paradoxalmente ela não fomenta a inovação, sendo um desestímulo em 
O aperfeiçoamento e o uso das novas tecnologias são necessidades prementes no novo modelo ${ }^{49}$, mas sua implementação não pode se limitar à mera integração às burocracias já existentes ${ }^{50}$, pois isso implicaria em automação. Todavia, importante destacar que nem sempre a automação é prejudicial. Ao contrário, às vezes sua utilização auxilia bastante a relação sociedade-governo, a exemplo do que ocorre com a declaração de imposto de renda, que pode ser facilmente preenchida pelo usuário no ambiente virtual. O que se pretende afirmar, é que o novo modelo exige uma mudança de mentalidade do gestor público, a fim de focar no usuário, e não somente no sistema.

\section{Smart Cities: políticas públicas guiadas a partir do Big Data (data driven cities)}

Nesse cenário de economia criativa, colaborativa e compartilhada (sharing economy), propiciada pelas tecnologias na sociedade em rede, surgem movimentos sociais e governamentais pretendendo a transformação das cidades em "cidades inteligentes" (Smart Cities) ou mesmo sua criação.

De acordo com Nobuyuki Tokoro, a expectativa é que as cidades inteligentes possam ser "um poderoso trunfo para resolver os vários problemas enfrentados hoje pelas cidades, incluindo crescimento da população urbana, envelhecimento da sociedade, congestionamento de trânsito e segurança" ${ }^{51}$.

Desta forma, os governos em cidades inteligentes são chamados a desempenhar um papel fundamental no desenvolvimento de capacidades nas cidades e eles estão cada vez mais usando as tecnologias da informação e comunicação (TIC) na criação de ambientes urbanos interativos, participativos e baseados em dados, bem como na melhoria dos serviços públicos e no funcionamento da administração. Eles estão aproveitando melhor a moderna infra-estrutura da TIC, o governo eletrônico e a cidadania, buscando produzir maiores resultados em relação à riqueza e ao valor público ${ }^{52}$.Smart Cities, segundo a definição traçada pela União Europeia, são "sistemas de pessoas interagindo e usando energia, materiais, serviços e financiamento para catalisar o desenvolvimento econômico e a melhoria da qualidade de vida" dentro das cidades. A inteligência relativa a esses fluxos está ligada ao uso "estratégico de infraestrutura e serviços e de informação e comunicação com planejamento e gestão urbana para dar resposta às necessidades sociais e econômicas da sociedade" 53 .

Em suma, as Smart Cities são cidades criativas e sustentáveis, que concomitantemente: (i) valem-se da tecnologia em seu processo de planejamento (devem criar um ecossistema capaz de gerar inovação e novas

razão do risco inerente à própria ilegalidade.

49 " [...] bureaucratic structures must be upgraded to accommodate the new technologies and their uses as the digital city hall replaces one based on paper, cities will have to jettison the structures of governance that have served them for more than a hundred years" CRAWDFORD, Susan; GOLDSMITH, Stephen. The responsive city: engaging communities through data-smart governance. San Francisco: Jossey-Bass, 2014. p. 1.

50 Diante desta necessidade de se superar as burocracias existentes, Valter Shuenquener de Araujo, em palestra ministrada no "I Fórum sobre Inovação no Direito Público: Diagnósticos e propostas" na Universidade Estadual do Rio de Janeiro no dia 07 de novembro de 2017, trouxe importantes exemplos de superações, em especial quanto ao poder de polícia e ao controle. Explicou Valter Shuenquener de Araujo que em razão da tecnologia hoje existente não há como negar a viabilidade de exercício do poder de polícia por particulares na Administração Pública, pois aplicativos permitem isso, como, por exemplo, o aplicativo Capester, que viabiliza que um particular tire uma foto ou filme uma infração de trânsito, e o Poder Público, valendo-se destas imagens, multe posteriormente o infrator. A tecnologia reforça o controle, bem como assegura uma maior validade, legitimidade em relação aos atos praticados por particulares a pretexto de se exercer o poder de polícia. Há também inovações tecnológicas revolucionárias no âmbito do Tribunal de Contas, que, por meio de técnicas de sensoriamento remoto, através de imagens, obtidas via satélites e/ ou de aeronaves tripuladas ou não, de aplicações de análise multicritério para informações geográficas, controla à distância obras públicas, despesas públicas e receitas em tempo real, suplantando aquela ideia de que o Tribunal de Contas deva atuar somente $a$ posteriori. ARAUJO, Valter Shuenquener de. Inovação e Administração pública. 2017. Rio de Janeiro: UERJ Reg. 2017. Disponível em: <https://www.facebook.com/uerjreg/videos/2065070117045188/>. Acesso em: 11 jan. 2018.

51 TOKORO, Nobuyuki. The smart city na the co-creation of value: a source of new competitiveness in a Low-carbon society. Japan: Springer, 2016. p. 2 (tradução livre)

52 BOLÍVAR, Manuel Pedro Rodríguez; LÓPEZ-QUILES, José Miguel. Smart Technologies for smart governments: a review of technological tools in smart cities. In: BOLÍVAR, Manuel Pedro Rodríguez. Smart technologies for smart governments: transparency, efficiency and organizational issues. Granada: Springer, 2018. v. 24. p. 3.

53 FUNDAÇÃO GETÚlIO VARGAS (FGV). O que é uma cidade inteligente? Disponível em: <http://fgvprojetos.fgv.br/ noticias/o-que-e-uma-cidade-inteligente>. Acesso em: 29 out. 2017. 
tecnologias); (ii) têm presente a participação da sociedade civil; (iii) fazem a coleta e o uso eficiente de enormes quantidades de dados, para que se forme uma camada de inteligência a ser utilizada pelos governantes em prol da população e que, também, possa ser utilizada pela própria população (Big Data).

Com relação ao último requisito constitutivo das cidades inteligentes (item iii), ou seja, o Big Data, há necessidade maior aprofundamento teórico da expressão para os fins deste trabalho.

Big Data, nas percepções de Kate Crawford e Jason Schultz, trata-se de expressão ampla, vaga e imprecisa $^{54}$, inexistindo a respeito uma definição uniforme. Por sua vez, Viktor Mayer-Schonberger e Kenneth Cukier dizem que o Big Data consiste na realização de determinadas coisas em grande escala, e que não podem ser realizadas em menor escala, de forma a extrair novas ideias ou criar novas formas de valor, de maneira que acabam mudando mercados, organizações, a relação entre os cidadãos e os governos, dentre outros $^{55}$.

A Diretiva 95/46/EC do Parlamento Europeu, em seu artigo 29, define Big Data como o crescimento exponencial tanto na disponibilidade quanto no uso automatizado de informação: refere-se a conjuntos de dados digitais gigantescos detidos por empresas, governos e outras organizações de grande porte, que são amplamente analisados usando algoritmos de computador. Big Data pode ser utilizado para identificar tendência mais gerais e correlações, mas também pode ser processado de modo a afetar diretamente os indivíduos ${ }^{56}$.

Kirk Borne ${ }^{57}$ sustenta que o Big Data é composto pelos seguintes elementos:

I) Volume (Volume): muitos dados; apelidado de Tonnabytes, haja vista que se trata, em um sentido metafórico, de "toneladas de bytes";

II) Variety (Variedade): complexidade, milhares ou muitas características por item de dados, grande dimensionalidade, explosão combinatória, muitos tipos de dados e muitos formatos de dados;

III) Velocity (Velocidade): alta taxa de dados e informações que fluem para dentro e para fora de nossos sistemas em tempo real;

IV) Veracity (Veracidade): dados necessários e suficientes para testar muitas hipóteses diferentes, vastas amostras de treinamento para a modelagem de formatos em microescala e a validação do modelo, a verdade micro-granulada de cada objeto em sua coleta de dados, capacitando assim a análise da "população inteira";

V) Validity (Validade): qualidade dos dados, governança, gerenciamento de dados mestres (MDM) em coletâneas de dados maciços, diversos, distribuídos, heterogêneos e "impuros";

VI) Value (Valor): trata-se do "V" mais importante, pois caracteriza o valor do negócio;

VII) Variability (Variabilidade): dados dinâmicos e evolutivos;

VIII) Venue (espaço): dados distribuídos, heterogêneos de múltiplas plataformas, de diferentes sistemas

54 CRAWFORD, Kate; SCHULTZ, Jason. Big data and due process: toward a framework to redress predictive privacy harms. Boston College Law, v. 55, n. 1. 2014. Disponível em: <http://lawdigitalcommons.bc.edu/bclr/vol55/iss1/4>. Acesso em: 30 out. 2017.

55 "Big data refers to things one can do at a large scale that cannot be done at a samaller one, to extract new insights or create new forms of value, in ways that change markets, organizations, the relationship between citzens and governments, and more" MAYER-SCHONBERGER, Viktor; CUKIER, Kenneth. Big data: a Revolution that will transform how we live, work and think. New York: Houghton Mifflin Harcourt, 2013. p. 6.

56 "Big data refers to the exponential growth both in the avalibility and in the automated use of information: it refers to gigantic digital datasets held by corporation, governments and other large organisations, which are then extensively analysed (hence the name: analytics) using computer algorithms. Big data can be used to identify more general trends and correlations but it can also be processed in order to directly affect individual" EUROPEAN COMMISSION. Opinion 03/2013 on purpose limitation. Disponível em: <http://ec.europa.eu/justice/data-protection/article-29/documentation/opinion-recommendation/files/2013/wp203_en.pdf>. Acesso em: 31 out. 2017.

57 BORNE, Kirk. Knowledge is power. 11 de abril de 2014. Disponível em: <https://mapr.com/blog/top-10-big-data-challengesserious-look-10-big-data-vs/>. Acesso em: 31 out. 2017. 
de proprietários, com diferentes requisitos de acesso e formatação; nuvem privada versus nuvem pública;

IX) Vocabulary (Vocabulário): esquema de modelos de dados, semânticas, ontologias, taxonomias e outros metadados baseados em conteúdo e contexto que descrevem a estrutura, sintaxe, conteúdo e proveniência dos dados;

X) Vagueness (Vagueza): confusão sobre o significado de grandes dados.

O Big Data constitui importante elemento para as Smart Cities, pois se trata de quantidades massivas de dados estruturados por meio de algoritmos (machine learning ${ }^{58}$ ) que proporcionam Inteligência às cidades quando devidamente processadas e analisadas.

Uma cidade inteligente, gerida por dados (data-driven city), é caracterizada pela capacidade de as agências de gestão da cidade valerem-se de tecnologias para geração e captação de fluxos de dados, para posterior processamento e análise ${ }^{59}$, destinados à adoção de soluções para melhoria dos padrões de vida dos moradores, trazendo desenvolvimento de áreas sociais, econômicas e ecológicas de ambiente urbano. Em outras palavras, o gerenciamento da cidade inteligente pode ser um motor básico para a transformação dos serviços e inovações da cidade e mudar significativamente princípios de gestão do meio ambiente urbano ${ }^{60}$.

O Big Data permite o acompanhamento de comportamentos humanos em tempo real e de maneira massificada e agregada, e, ao mesmo tempo, destacar seguimentos a partir dos próprios comportamentos. E isso, do ponto de vista das ciências sociais, é inédito.

O momento atual viabilizou meios poderosíssimos de promoção da cooperação social trazidos pelas plataformas digitais em todos os sentidos. Mas, ao mesmo tempo, nunca esses meios foram tão apropriados por interesses privados, em que impera, na maioria das vezes, a racionalidade empresarial, com base em uma "economia da atenção" (e aqui se destaca obra de Nir Eyal), criando plataformas que captam a atenção

58 "O desenvolvimento da tecnologia da Inteligência Artificial (IA) está conferindo a computadores a capacidade de aprender e atuar de forma autônoma, ou seja, independente de uma instrução específica de um ser humano" PIRES, Thatiane Cristina Fontão; SILVA, Rafael Peteffi da. A responsabilidade civil pelos atos autônomos da inteligência artificial: notas iniciais sobre a resolução do Parlamento Europeu. Revista Brasileira de Políticas Públicas, v. 7, n. 3, 2017.

59 É necessário que haja o processamento e análise dos dados para gerar informação e conhecimento. Nesta esteira, "importante entender que os dados se diferenciam da informação e do conhecimento. Colocada a questão de forma bastante simplificada, os dados podem ser considerados como matérias-primas da informação e a informação pode ser considerada matéria-prima do conhecimento, visto este como o resultado de uma reflexão mais consistente - e preferencialmente suscetível de aplicação - a respeito de informações sobre determinada área ou assunto. Tal distinção é importante porque os dados importam, do ponto de vista econômico, na medida em que podem ser convertidos em informações necessárias ou úteis para a atividade econômica. Os dados precisam, portanto, ser processados e trabalhados para que possam gerar valor. Se tal constatação não afasta a importância em si dos dados isolados ou "crus", tem o importante papel de realçar o fato de que o mero acesso a dados, sem a possibilidade efetiva e eficiente de transformá-los em informação, pode ser insuficiente para resolver diversos problemas competitivos” FRAZÃO, Ana. Big data e impactos sobre a análise concorrencial: direito da concorrência é um dos mais afetados pela importância dos dados - parte 1 . 29 de novembro de 2017. Disponível em: < https://www.jota.info/colunas/constituicao-empresa-e-mercado/big-data-e-impactossobre-a-analise-concorrencial-29112017> . Acesso em: 10 jan. 2018.

60 A data-driven city is characterised by ability of agencies of city management to use technologies for generation of data flows, their processing and analysis aimed for adoption of solutions for improvement of living standards of residents thanks to development of social, economic and ecological areas of urban environment. In other words, management of datadriven city may be a basic driver for transformation of city services and innovations and significantly change management principles of urban environment. PWC. Data-driven cities: form concept to applied solutions. p. 4. Disponível em: <https://www.pwc.ru/en/government-and-public-sector/assets/ddc_eng.pdf>. Acesso em: 30 out. 2017.

61 De acordo com Nir Eyal, as tecnologias que utilizamos tornaram-se compulsões, se não adições de pleno direito. É o impulso de verificar uma notificação de mensagem. É a atração para visitar o YouTube, o Facebook ou o Twitter por apenas alguns minutos, apenas para encontrar-se ainda tocando e deslizando uma hora depois. É o desejo que você provavelmente sente ao longo do seu dia, mas dificilmente avisa. Os psicólogos cognitivos definem os hábitos como "comportamentos automáticos desencadeados por pistas situacionais": o que fazemos com pouco ou nenhum pensamento consciente. Os produtos e serviços que usamos alteram, habitualmente, nosso comportamento cotidiano, assim como os designers pretendiam. Nossas ações foram projetadas. Como as empresas, produzindo pouco mais do que os bits de código exibidos em uma tela, aparentemente controlam as mentes dos usuários? O que faz com que alguns produtos formem hábitos? Formar hábitos é imperativo para a sobrevivência de muitos produtos. Para formar esse hábito, a economia da atenção segue o "Modelo Hook", que se estrutura basicamente em 4 etapas-chave de cada loop: 1. Gatilho: como o ciclo inicia? No início, isto pode ser através de disparadores externos (como um e-mail, notificação, emblema de ícone etc.), 
dos usuários, a fim obter lucro direto ou indireto ( $v . g .:$ publicidades direcionadas), por meio da manipulação das informações que esses dispositivos digitais captam dos comportamentos involuntários de seus usuários. Os gigantes da internet observam os comportamentos humanos para obter mais lucro. Por isso se cunhou a famosa frase (repetida a esmo) "Os dados são o novo petróleo" (Data is the new oil), porque "governos e empresas têm conscientemente tratado dados pessoais com mercadoria" ${ }^{2}$.

A utilização de instrumentos cooperativos pelos detentores da tecnologia e da inovação na cultura digital para promover melhoria na vida das cidades revela que o nosso espaço urbano é cada vez mais fundamentalmente privatizado. A exemplo do que vem ocorrendo com acoplamento da tecnologia privada ao mobiliário urbano, em que torna a cidade extremamente dependente da tecnologia privada para melhorias do fluxo viário. Prova dessa dependência pode ser demonstrada por uma recente falha ocorrida no aplicativo Waze, que acabou congestionando o trânsito da cidade de São Paulo no dia 23 de outubro de 2017, isso se dando por estarem os motoristas da cidade cada vez mais dependentes da tecnologia e confiarem até mais no referido serviço do que no próprio instinto de condutor ${ }^{63}$. A confiança é a base estrutural dessas plataformas, motivo por que a quebra de confiança nos serviços pode gerar o abandono do sistema pelos usuários e o retrocesso em termos de mobilidade urbana.

O mesmo se diga com relação aos recentes bloqueios judiciais dos serviços de Whatsapp por descumprimentos de ordens judiciais de abertura de dados ${ }^{64}$, que deixaram cerca de 120 milhões de usuários no Brasil ${ }^{65}$ temporariamente sem acesso a essa popular e nova forma de liberdade de expressão comunicacional (artigo $5^{\circ}$, IX, da Constituição Federal de 1988) ${ }^{66}$. Face a essa violação difusa ao direito fundamental desta liberdade de expressão, Celso Antonio Pacheco Fiorillo e Renata Marques Ferreira sustentam que tal suspensão violou "o preceito fundamental de liberdade de expressão aqui indicado, bem como a legislação de regência

mas, por meio de loops sucessivos, o usuário, eventualmente, cria disparadores internos em que um pensamento ou emoção particular os enviará de volta ao seu produto; 2. Ação: Uma vez que o usuário está ciente, eles precisam usar seu produto (por meio do gatilho), qual é a ação mais simples que eles podem realizar para obter algum tipo de recompensa. Por exemplo, um "Like" do Facebook [e acrescentamos prêmios aos que contribuem com sinalizações de tráfego no aplicativo Waze]; 3. Recompensa variável: como eles são recompensados por esse comportamento? Isso pode ser a validação social (por exemplo, “meus amigos aprovam!'), Coleção de recursos materiais (por exemplo, adicionar uma foto a uma coleção) ou gratificação pessoal (por exemplo, caixa de entrada zero). A parte "variável" é importante — as recompensas nem sempre devem ser previsíveis, incentivando os usuários a repetir o ciclo; 4. Investimento: Finalmente, o usuário precisa colocar algo de volta para aumentar a chance de repetir o loop. Isso pode ser conteúdo (por exemplo, um livro em seu Kindle), dados inseridos pelo usuário (por exemplo, informações de perfil ou contas vinculadas), reputação (por exemplo, algo para obter uma revisão de vendedor de 5 estrelas) ou uma habilidade aprendida (por exemplo, agora sou realmente bom neste programa de software). O investimento também configura o gatilho para o próximo ciclo do loop. EYAL, Nir. Hooked: How to build habit-forming products. New York: Penguin Group, 2014. (livro digital - Kindle).

62 VANIAN, Jonathan. Why data is the new oil. Fortune, July 2016. Disponível em: < http://fortune.com/2016/07/11/data-oilbrainstorm-tech/>. Acesso em: 31 out. 2017. Ver também: MAYER-SCHONBERGER, Viktor; CUKIER, Kenneth. Big data: a Revolution that will transform how we live, work and think. New York: Houghton Mifflin Harcourt, 2013. p. 16

63 KLEINA, Nilton. Erro no Waze deixa trânsito de São Paulo (ainda mais) congestionado. 25 de outubro de 2017. Disponível em: <https://www.tecmundo.com.br/mobilidade-urbana-smart-cities/123450-erro-waze-deixa-transito-paulo-ainda-congestionado. htm>. Acesso em: 31 out. 2017.

64 "O aplicativo de mensagens instantâneas WhatsApp foi alvo de quatro decisões de bloqueio no Brasil, três delas que foram levadas a cabo, por não entregar conteúdo de comunicações de investigados em inquéritos e processos penais. Desde o momento em que implementou a chamada ‘criptografia de ponta a ponta`, a empresa responsável pelo aplicativo tem reiterado a impossibilidade técnica de cumprir ordens judiciais de interceptação. Diante disso, o então Ministro da Justiça Alexandre de Moraes declarou as intenções de trazer um projeto de lei que regularia aplicativos de mensagens que utilizam criptografia e o Supremo Tribunal Federal convocou audiência pública para entender as complexidades técnicas dessa tecnologia" ABREU, Jacqueline de Souza. Passado, presente e futuro da criptografia forte: desenvolvimento tecnológico e regulação. Revista Brasileira de Políticas Públicas, v. 7, n. 3, 2017. 65 OLHAR DIGITAL. Whats App revela número de usuários no Brasil. 29 de maio de 2017. Disponível em: < https://olhardigital.com. br/noticia/whatsapp-revela-numero-de-usuarios-no-brasil/68604>. Acesso em: 11 jan. 2018.

66 A comunicação é indispensável para que a interação ocorra no âmbito social, e inter-relaciona-se com a liberdade e a dignidade da pessoa humana, sendo que estas não existem sem aquela. ARAUJO, Marilene; SANTOS, Maria Celeste Cordeiro Leite dos. O tempo e o espaço. Fragmentos do marco civil da internet: paradigmas de proteção da dignidade humana. Revista Brasileira de Políticas Públicas, v. 7, n. 3, 2017. 
sobre o tema" ${ }^{97}$, em específico o artigo 30 , incisos I e II da Lei 12.965/2014 (Marco Civil da Internet), ${ }^{68}$ que dispõe que o uso da internet no país tem como um dos princípios a "garantia da liberdade de expressão, comunicação e manifestação do pensamento, nos termos da Constituição Federal” (inciso I) e que se deve preservar a "estabilidade, segurança e funcionalidade da rede, por meio de medidas técnicas compatíveis com os padrões internacionais e pelo estímulo ao uso de boas práticas"(inciso V).

Em que pese o Big Data poder ser um grande aliado da democracia, pode gerar ainda mais exclusão social nas cidades daqueles que a ela não têm acesso à internet, seja por meio de banda larga fixa ou móvel, e esse fator é de considerável importância para efeito de políticas públicas em Smart Cities, em especial pelo fato de o Brasil ser um dos dez países do mundo com maior número de pessoas desconectadas, como indica um novo estudo encomendado pela Internet.org à unidade de inteligência da revista britânica The Economist. No total, 70,5 milhões de brasileiros estão offline, isto é, não possuem acesso à internet, seja por meio de banda larga fixa ou móvel ${ }^{6}$.

As cidades exacerbam muitas vezes as desigualdades, as lacunas entre as diferenças dos cidadãos, fazendo como que o exercício do direito à cidade não ocorra de forma igualitária para todos.

Aplicativos para smatphones como, por exemplo, "Pelas Ruas"70 e "LevelUp" ", em que os próprios cidadãos coletam dados, que são mapeados e encaminhados ao Poder Público para se criar políticas públicas, não conseguem captar a visão das pessoas sem acesso à internet no planejamento urbano.

As pessoas que hoje têm acesso à internet e smartphones são em grande parte grupos dominantes, o que acaba gerando um desnível muito grande de informação, em especial nas periferias dos grandes centros.

A malha da Cidade Inteligente (Smart City) é composta por pessoas, instituições, empresas, e podem ensejar diferentes visões; a inclusão de todas essas visões é fundamental no processo democrático. Por isso, fala-se hoje em um direito humano de acesso à internet, pois, como bem aponta Bárbara Luiza Coutinho do Nascimento ${ }^{72}$, "enquadra-se como direito humano aquele que é decisivamente constitutivo da manutenção da dignidade humana em determinado contexto histórico" - em que pese não esteja presente esse direito em um rol taxativo, deve-se, com espeque em André de Carvalho Ramos, reconhecer a existência de uma cláusula aberta (de princípio de não-tipicidade) dos direitos humanos, ou seja, os direitos humanos merecem proteção em virtude do seu conteúdo, e não por constarem de um rol em um instrumento constitucional ou internacional ${ }^{73}$.

São necessárias soluções de infraestrutura, pois se forem mantidas as infraestruturas presentes, como wi-fi público somente em ambientes públicos mais elitizados, como aeroportos, estarão sendo ocultados dados importantes para a implementação de políticas públicas, e não serão contempladas as cidades como um todo, gerando assim distorções ainda mais graves.

Com a inclusão digital, há viabilidade de potencial de empoderamento às pessoas, que passam a ter mais

67 FERREIRA, Renata Marques; FIORILLO, Celso Antonio Pacheco. Tutela jurídica do Whatsapp na sociedade da informação. Rio de Janeiro: Lumen Juris, 2017. p. 104.

68 BRASIL. Lei no 12.965, de 23 de abril de 2014. Disponível em: <http://www.planalto.gov.br/CCIVIL_03/_Ato2011-2014/2014/ Lei/L12965.htm>. Acesso em: 31 out. 2017.

69 THE ECONOMIST. The inclusive internet index: bridging digital divides. 2017. Disponível em: < https:// theinclusiveinternet.eiu. com/assets/external/downloads/3i-bridging-digital-divides.pdf>. Acesso em: 31 out. 2017.

70 O aplicativo para smartphones "Pelas Ruas" é uma plataforma colaborativa em que usuários podem compartilhar e discutir problemas urbanos de Porto Alegre e Região Metropolitana. A ideia é de que o cidadão utilize o celular para apontar o que não está bom na cidade. A partir de foto e descrição, situações como buraco de rua ou fios de energia elétrica caídos podem ser vistos por mais pessoas e chegar aos responsáveis por soluções, criando uma comunidade online engajada.

71 Aplicativo destinado a denunciar o desperdício de água. A ideia que virou aplicativo foi criada por quatro alunos universitários e levou o primeiro lugar na premiação do programa Benchmarking Brasil.

72 NASCIMENTO, Barbara Luiza Coutinho do. O direito bumano de acesso à internet: fundamentos, conteúdo e exigibilidade. Rio de Janeiro, 2013 (livro digital).

73 RAMOS, André de Carvalho. Teoria geral dos direitos humanos na Ordem Internacional. Rio de janeiro: Renovar, 2005. p. 221 
vozes, viabilizando um olhar para novas realidades, inclusive, quebrando o monopólio de mídias digitais. Hoje conseguimos ver que tem esse potencial, mas por outro lado temos um aprofundamento muito grande de monopólios, de concentração de poder, renda e toda lógica contrária disso.

O uso do Big Data por empresas detentoras de aplicativos pode gerar condutas discriminatórias, potencializando a exclusão de zonas periféricas, em especial aquelas com desafios de segurança pública, como ocorreu com o aplicativo Uber, cujos serviços não cobrem algumas regiões da cidade, principalmente na periferia. No caso da cidade de São Paulo, na região da Vila Brasilândia, em razão da dificuldade de se conseguir carro da Uber, moradores da área criaram um serviço paralelo e mais precário utilizando-se do Whatsapp, ou seja, sem a criação de uma plataforma própria por ausência de tecnologias como sistemas de geolocalização e de reputação de usuários e motoristas $^{74}$. Isso demonstra o como os detentores da tecnologia modulam nossas vidas em cidades, e que cidadãos, em contrapartida, mesmo em condições desfavoráveis de políticas de educação, têm potenciais estratégicos para rumarem para os comportamentos que a sociedade excluída deseja, ainda que com a ausência de potencial inovador e tecnológico.

Com base em dados coletados, comumente sem qualquer controle democrático, empresas categorizam quais indivíduos são de "interesse comercial”, gerando, assim, segregação social, violando-se a isonomia e a dignidade da pessoa humana ${ }^{75}$.

O Big Data, também, pode colocar em cheque questões de privacidade, tornando as cidades inteligentes policialescas, diante da viabilidade de intensos monitoramento e vigilância de seus cidadãos. Importante mencionar que a Corte de Justiça da União Europeia divulgou em 21/12/2016 o resultado do julgamento dos casos C-203/15 e C-698/15 que versavam sobre questionamentos de regras que impunham o arquivamento indiscriminado de dados relativos à localização de tráfego de dados em comunicações eletrônicas, evolvendo cidadãos da Irlanda, Noruega e Reino Unido, abrindo relevante debate sobre o acesso a tais informações, o que, por certo, implica em risco de vigilância excessiva, notadamente por parte das empresas que guardam os dados e dos Estados que podem ter acesso a eles. Por meio de decisão definitiva da qual não cabe mais recurso, a Corte Europeia decidiu que Estados-membros não podem impor uma obrigação geral de conservar dados das comunicações eletrônicas, pois tal medida violaria verdadeiro ato de vigilância indiscriminada, incompatível com os direitos fundamentais, violando a proporcionalidade, razoabilidade e os valores inscritos em uma sociedade democrática ${ }^{76}$.

Nessa esteira, cumpre ainda lembrar o Sistema de Crédito Social Chinês, em que a China, com população acima de 1 bilhão de habitantes, pretende lançar um programa de pontuação sobre os seus cidadãos, classificando-os de acordo com as informações contidas em um enorme banco de dados, alimentado com milhares de informações pessoais (em grande maioria coletadas pela internet), tais como histórico de navegação na internet, itens adquiridos em compras, probabilidade de adimplemento das obrigações, etc. ${ }^{77}$ Diante desse contexto de desafios da Big Data frente à privacidade, sábias as palavras de Zygmunt Bauman e David Lyon: "no final a escolha é entre segurança e liberdade: você precisa de ambas, mas não pode ter uma sem sacrificar pelo menos parte da outra; e quanto mais tiver de uma, menos terá da outra". E continuam os referidos autores: "Em matéria de segurança, as comunidades ao estilo antigo batem de longe as redes. Em matéria de liberdade, é exatamente o contrário (afinal, basta pressionar a tecla 'delete' ou decidir parar

74 SOUZA, Felipe. Moradores da periferia de São Paulo criam a Ubra para bairro vetado pelo Uber. 15 de março de 2017. Disponível em: $<$ https://g1.globo.com/brasil/noticia/moradores-de-periferia-de-sp-criam-a-ubra-para-bairro-vetado-pelo-uber.ghtml>. Acesso em: 31 out. 2017.

75 BEZERRA, Tiago José de Souza Lima; MENEZES NETO, Elias Jacob de; MORAIS, Jose Luis Bolzan de. O projeto de lei de proteção de dados pessoais (PL 5267/2016) no mundo do big data: o fenômeno da dataveillance em relação à utilização de metadados e seu impacto nos direitos humanos. Revista Brasileira de Políticas Públicas, v. 7, n. 3, 2017.

76 GOMES, Rodrigo Dias de Pinho. Big Data: desafios à tutela da pessoa humana na sociedade da informação. Rio de Janeiro: Lumen Juris, 2017. p. 50-51.

77 GOMES, Rodrigo Dias de Pinho. Big Data: desafios à tutela da pessoa humana na sociedade da informação. Rio de Janeiro: Lumen Juris, 2017. p. 52-53. 
de responder a mensagens para se livrar de sua interferência)" "78.

De acordo com Giampaolo Poggio Smanio, “as políticas públicas pressupõem as relações do Estado com a sociedade, pois a via da participação dos cidadãos deve ser o método a ser buscado, tanto para sua formulação, quanto para sua execução"79. Por isso as Smart Cities (mesmo com os problemas apontados) podem cumprir importante interface de diálogos entre sociedade e prefeituras/empresas de aplicativos para elevar o nível de efetividade das decisões públicas dentre os variados interesses envolvidos a partir da sociedade opinando, bem como melhorando a execução dessa decisões, dependendo para tanto, especialmente, de "infraestrutura de acesso tecnológico" 80 que propicie maior reconhecimento e inclusividade dos indivíduos na webesfera a fim de se atingir o verdadeiro escopo colaborativo das novas tecnologias digitais, afinal, nas lições de Luciana Cristina Souza, "a garantia de maior atuação dos cidadãos nessa webesfera depende muito mais da postura a ser adotada pelo Poder Público, [...] do que dos instrumentos tecnológicos" ${ }^{\text {. }}$.

\section{Concorrência e Big Data Business relevantes às Smart Cities: estudo de caso ENVOLVENDO A AQUISIÇÃo do WAZE PELO GOOGLE}

Como visto, empresas de aplicativos que trabalham com Big Data geram grande impacto nas Cidades Inteligentes (Big Data Business relevantes às Smart Cities), daí a importância de se estudar a questão das políticas concorrenciais ligadas a essas poucas empresas detentoras de tecnologia e poder econômico manifesto.

Concorrência, de forma objetiva, pode ser definida como a disputa entre agentes que desenvolvem uma atividade econômica lícita em um mesmo segmento do mercado.

O artigo 170, inciso IV da Constituição Federal de 1988, prevê a livre concorrência como um princípio da ordem econômica, "fundada na valorização do trabalho humano e na livre iniciativa", tendo por objetivo "assegurar a todos a existência digna, conformes os ditames da justiça social". Nas lições de José Inácio Gonzaga Franceschini e Vicente Bagnoli, encontra-se no referido princípio “o fundamento da economia de mercado, onde os agentes econômicos devem travar suas disputas, da qual o melhor, o mais apto, conseguirá a vitória, sobrepondo-se aos seus rivais", sendo esse "ambiente de livre concorrência" que tenderá a propiciar "resultados mais eficientes, com inovações tecnológicas, aumento da qualidade de produtos e serviços, reduções de custos - e consequentemente de preços", contribuindo "efetivamente para o desenvolvimento" e trazendo ganhos ao bem-estar econômico do consumidor" ${ }^{\prime \prime 2}$.

Em que pese o texto constitucional aludir à livre concorrência, é cediço que ela só teria lugar em no plano ideal, haja vista que, no mundo real, imperam, constantemente, os abusos do poder econômico ${ }^{83}$, afinal, nos dizeres de Eros Roberto Grau, "o poder econômico é a regra e não a exceção" ${ }^{84}$. Assim, a fim de garantir a livre concorrência, necessária a sua composição com outro princípio latente, ocultado sob o manto de norma no artigo 173, \ $3^{\circ}$ da Constituição Federal de 1988, que se expressa como "princípio da repressão aos abusos do poder econômico" ${ }^{\prime 5}$.

78 ZYGMUNT, Bauman; LYON, David. Vigilancia líquida. Tradução: Carlos Alberto Medeiros. Rio de Janeiro: Zahar, 2013. p. 31. 79 SMANIO, Gianpaolo Poggio. Legitimidade jurídica das políticas públicas: a efetivação da cidadania. BERTOLIN, Patricia Tuma Martins; SMANIO, Gianpaolo Poggio (Org.). O direito e as políticas públicas no Brasil. São Paulo: Atlas, 2013. p. 10

80 SOUZA, Luciana Cristina. Dignidade humana na webesfera governamental brasileira. Revista Brasileira de Políticas Públicas, v. 7 , n. 3, 2017.

81 SOUZA, Luciana Cristina. Dignidade humana na webesfera governamental brasileira. Revista Brasileira de Politicas Públicas, v. 7 , n. 3, 2017.

82 BAGNOLI, Vicente; FRANCESCHINI, José Inácio Gonzaga. Direito concorrencial. In: CARVALHOSA, Modesto (Coord.). Coleção tratado de direito empresarial. 2016. v. 7. p. 188-189.

83 GRAU, Eros Roberto. A ordem econômica na Constituição de 1988. 17. ed. São Paulo: Malheiros, p. 206-207.

84 GRAU, Eros Roberto. A ordem econômica na Constituição de 1988. 17. ed. São Paulo: Malheiros, p. 207.

85 GRAU, Eros Roberto. A ordem econômica na Constituição de 1988. 17. ed. São Paulo: Malheiros, p. 207. 
O referido valor constitucional é reproduzido na Lei de Concorrência (Lei 12.529/2011), sendo este o paradigma orientador da prevenção e repressão às infrações contra a ordem econômica e "cujos valores tutelados pela lei encontram na coletividade o seu legítimo titular" ${ }^{\prime \prime 6}$.

A política de concorrência, abeberando-se em uma economia neoclássica como aparato analítico, ao longo do século XX, estruturou-se na denominada Teoria Estática da concorrência, que é aquela que se preocupa com o nível dos preços (esfera da circulação), com a "tendência à eliminação de vantagens ou de diferenças entre os agentes - a dimensão passiva da concorrência" ${ }^{\prime 7}$.

Outra forma de estruturar a política da concorrência, em contraste com a visão estática tradicional, diz respeito à denominada Teoria da Concorrência dinâmica (concorrência Schumpeteriana, em alusão ao seu autor J. Schumpeter), em que não se contenta somente com o monitoramento dos efeitos negativos dos concorrentes já existentes, mas se preocupando em criar concorrentes novos (dimensão ativa da concorrência). A compreensão do capitalismo não deve se limitar à esfera da circulação de produtos e serviços (que é a esfera dos preços), mas sim à esfera da produção (que é a esfera na qual novos produtos e serviços são criados).

Segundo Schumpeter, o capitalismo — como já dizia Marx — é um processo evolutivo, impulsionado pelo advento de novos bens a serem colocados à disposição dos consumidores, novos métodos de produção e de transporte, novos mercados e novas formas de organização industrial. A inovação na seara econômica incessantemente revoluciona o mercado, reiteradamente destruindo a ordem econômica antiga para criar uma nova. Para Schumpeter, esse processo de 'destruição criativa' consiste na essência do capitalismo ${ }^{88}$.

Sob uma ótica Schumpeteriana, sustenta Ana Frazão que "a economia disruptiva e outros novos modelos de negócios, portanto, se utilizam das facilidades proporcionadas pela tecnologia da informação para criar novos serviços ou mesmo criar novos modelos de negócios", isso por meio da "agregação da estrutura tecnológica a serviços já existentes, como se pode perceber nas manifestações de economia compartilhada no âmbito do transporte de passageiros" [v.g.: Uber]; "na tecnologia VoIP (voice over internet protocol), capaz de desempenhar função análoga à da telefonia" [v.g.: whatsapp]; "no streaming de vídeos on demand, em contraposição à televisão por assinatura tradicional; entre outros" $"$.

Dentro desse enfoque schumpeteriano acerca de inovações em sentido amplo, deve-se salientar que a ênfase a ser dada não diz respeito, somente, à mudança tecnológica - como erroneamente alguns vêm tratando de forma reducionista a sua teoria. O campo de incidência é maior, abrangendo toda e qualquer mudança no espaço econômico, promovida pelas empresas em busca de vantagens e consequentes ganhos competitivos.

Frente a essa análise, estamos aptos a investigar o campo concorrencial relativa ao Big Data Business relevantes às Smart Cities.

Em uma sociedade em rede em que os intangíveis ${ }^{90}$ produzidos pela tecnologia tornaram-se visíveis em razão dos seus reflexos no mundo físico, a economia criativa e disruptiva ganha fôlego, em especial pela natureza exponencial e infinita dessa nova forma de economia. São os intangíveis tecnológicos a chave para a sustentabilidade, pois permitem compartilhar (sharing economy) — mapeia-se o que já existe (espaços, equi-

86 BAGNOLI, Vicente; FRANCESCHINI, José Inácio Gonzaga. Direito concorrencial. In: CARVALHOSA, Modesto (Coord.). Coleção tratado de direito empresarial. 2016. v. 7. p. 189.

87 POSSAS, M. L. Concorrência Schumpeteriana. In: KUPPER, David; HASENCLEVER, Lia (Org.). Economia industrial: fundamentos teóricos e prática no Brasil. Rio de Janeiro: Campus, 2002. v. 1. p. 415-429.

88 SCHUMPETER, Joseph A. Capitalism, socialism \& democracy. Londres: Routledge, 2013. p. 83-84 (tradução livre).

89 FRAZÃO, Ana. Direito da concorrência: pressupostos e perspectivas. São Paulo: Saraiva Jur, 2017. p. 59. No mesmo sentido, confira-se: SILVA, José Benedito Lázaro da. O efeito disruptivo das inovações tecnológicas frente às ciências jurídicas e sociais. In: FEIGELSON, Bruno; FREITAS, Rafael Véras de; RIBEIRO, Leonardo Coelho (Coord.). Regulação e novas tecnologias. Belo Horizonte: Fórum, 2017. p. 159.

90 v.g.: propriedade intelectual, capital organizacional, conteúdos gerados pelo usuário e capital humano. 
pamentos, matérias primas pré-existentes) - e criar sistemas para melhor aproveitamento do pré-existente (otimização dos excedentes).

Uma sociedade preparada para manipular o big data (ativo intangível) e que, por meio dele, consiga inovar, criando novos produtos e serviços, bem como novos modelos de negócios, gera desenvolvimento alavancando a economia nacional.

Dentro da lógica concorrencial Schumpeteriana, ganha-se importância a inovação (economia criativa), devendo o Estado adotar políticas públicas para que a sociedade brasileira tenha condições de concorrer com grandes empresas de tecnologia de aplicativos que impactam as cidades (sobretudo estrangeiras ${ }^{91}$ ), para que o Brasil não fique à mercê destas, afinal, nas palavras de Martin Wolf: "se a economia de uma país não estiver no jogo da tecnologia, não participará de maneira alguma dos jogos econômicos do futuro" 22 . Para tanto, o Estado brasileiro deverá promover e incentivar o "desenvolvimento científico, a pesquisa, a capacitação científica e tecnológica e a inovação”, cumprindo, assim, o artigo 218 da Constituição Federal.

Sem a adoção de políticas públicas de longo prazo, a racionalidade empresarial continuará utilizando-se de estratégias anticoncorrenciais sensíveis envolvendo Big Data, criando monopólios em determinados setores, tal como ocorreu na aquisição do Waze pelo Google pelo valor aproximado de 1 bilhão de dólares.

A referida aquisição representou um ativo relevantíssimo, que é a massa de dados (Big Data) relativa ao transporte de veículos e a capacidade analítica desses dados para fins de mobilidade urbana. É fato que o interesse do Google nessa aquisição não é o consumidor e questões relacionadas à mobilidade urbana, mas sim a obtenção de dados e a possibilidade de impedir que concorrentes, como Apple e Facebook, ganhem força no setor" "' "Frustra-se, assim, a suposição de que o mercado esteja organizado, naturalmente em função do consumidor" "94 nas lições de Eros Roberto Grau. Ao que tudo indica, a aquisição teve por escopo criar uma barreira à entrada de novos concorrentes, impedindo que outro player captasse aquela tecnologia.

A estratégia de adquirir a tecnologia como forma de impedir a concorrência está no ecossistema de inovação tecnológica, e isso pode gerar a concentração e econômica e a barreira de entrada (prática monopolista $)^{95}$, sendo condutas que podem constituir infrações capituladas no artigo $36, \int 3^{\circ}$, incisos IV e V da lei antitruste (Le 12.529/2011), quais sejam: IV - criar dificuldades à constituição, ao funcionamento ou ao desenvolvimento de empresa concorrente ou de fornecedor, adquirente ou financiador de bens ou serviços; e V - impedir o acesso de concorrente às fontes de insumo, matérias-primas, equipamentos ou tecnologia, bem como aos canais de distribuição.

A adoção de uma política de concorrência unicamente sancionatória, todavia, é insuficiente. Devemos adotar políticas públicas de longo prazo que criem incentivos à inovação e à pesquisa científica e tecnológica

91 "Oito das empresas mais valiosas do planeta operam no setor de tecnologia. A capitalização de mercado combinada dessas companhias é de US\$ 4,7 trilhões. Isso representa 30\% da capitalização de mercado combinada das outras 92 companhias que formam o grupo de 100 empresas mundiais mais valiosas. Dessas oito companhias, cinco (Apple, Alphabet, Microsoft, Amazon e Facebok) são dos Estados Unidos, duas (Alibaba e Tencent) da China e uma (Samsung) da Coreia do Sul. A empresa de tecnologia europeia com capitalização de mercado mais alta, a SAP, ocupa o $60^{\circ}$ posto entre as empresas de maior capitalização no planeta" WOLF, Martin. Não devemos entregar nosso futuro às empresas de tecnologia. 16 de novembro de 2017. Disponível em: < http:// www1.folha.uol.com.br/colunas/martinwolf/2017/11/1935811-nao-devemos-entregar-nosso-futuro-as-empresas-de-tecnologia. shtml?loggedpaywall>. Acesso em: 10 jan. 2018.

92 WOLF, Martin. Não devemos entregar nosso futuro às empresas de tecnologia. 16 de novembro de 2017. Disponível em: <http:// www1.folha.uol.com.br/colunas/martinwolf/2017/11/1935811-nao-devemos-entregar-nosso-futuro-as-empresas-de-tecnologia. shtml?loggedpaywall>. Acesso em: 10 jan. 2018.

93 OLHAR DIGITAL. 4 motivos pelos quais o google compron o waze. Disponível em: < https://olhardigital.com.br/noticia/4-motivospelo-qual-o-google-comprou-o-waze/35180>. Acesso em: 31 out. 2017.

94 GRAU, Eros Roberto. A ordem econômica na Constituição de 1988. 17. ed. São Paulo: Malheiros, p. 207.

95 "Os gigantes da tecnologia deveriam ser rigorosamente impedidos de adquirir potenciais concorrentes. Isso certamente é anticompetitivo" WOLF, Martin. Não devemos entregar nosso futuro às empresas de tecnologia. 16 de novembro de 2017. Disponível em: <http://www1.folha.uol.com.br/colunas/martinwolf/2017/11/1935811-nao-devemos-entregar-nosso-futuro-as-empresas-detecnologia.shtml?loggedpaywall>. Acesso em: 10 jan. 2018. 
no ambiente produtivo (Lei n $\left.{ }^{\circ} 10.973 / 2004\right)$ a fim de que haja criação de concorrentes que criem tecnologia e propiciem o desenvolvimento, saindo da situação da posição de país consumidor de tecnologia alheia. Para tanto, a nossa democracia deve passar pela democratização do acesso à educação que será uma base para forjar outros concorrentes e dar alternativas de longo prazo. O maior ativo é o cérebro dos brasileiros, a criatividade. O grande ativo é que poderá cuidar das presentes e futuras gerações.

É inevitável que a economia criativa, que tem por centralidade os ativos intangíveis, torne-se a primeira estratégia de desenvolvimento dos territórios, Estados e países, pois é a única forma de se chegar à sustentabilidade, pois são os únicos recursos que não se esgotam, mas se multiplicam com o uso. Além de gerar resultados financeiros, geram, também, resultados sociais, ambientais e culturais. É, portanto, inevitável que a economia criativa se torne prioridade.

Nas palavras de Amartya Sen, "as recompensas do desenvolvimento vão muito além da melhora direta da qualidade de vida", e incluem também "sua influência sobre habilidade produtivas das pessoas, e, portanto, sobre o crescimento econômico em uma base amplamente compartilhada. Saber ler e fazer contas ajuda as massas a participar do processo de expansão econômica"96.

\section{Considerações finais}

A urbanização desordenada das cidades, fenômeno característico do Estado, inclusive brasileiro, nas últimas décadas, com a saturação demográfica de seu espaço geográfico urbano, tem acarretado inúmeros problemas sociais, tanto ao indivíduo como à sociedade, como os relativos à instalação de habitações precárias, implantação de transporte público inadequado, poluição ambiental, precariedade da segurança pública e saneamento básico inadequado.

O terceiro milênio, dando início à Era da Informação, é marcado pelo nascimento de uma "sociedade em rede", com avanços da tecnologia da informação e da comunicação, com a geração de expressivos reflexos sociais, inclusive no tocante às cidades.

Em um contexto de sociedade em redes, as demandas por cidades inteligentes (Smart Cities) são crescentes, em especial pelos impactos benéficos provocados pela tecnologia no "mundo real", nas cidades. Essas cidades valem-se, concomitantemente, de tecnologia, colaboração dos cidadãos e Big Data.

Empresas detentoras de tecnologia apropriam-se do Big Data e inventam aplicativos inovadores que interagem na cidade, agregando estrutura tecnológica ao aparato municipal de forma mais barata e eficiente, preterindo a ordem econômica até então vigente. Isso passa, necessariamente, pelo uso eficiente de dados e absorção de novas tecnologias e modelos de negócios.

O Big Data, um dos fenômenos inerentes à Era da Informação, possibilita o acompanhamento de comportamentos humanos em tempo real e de maneira massificada, proporcionando inteligência às cidades, quando devidamente processados e analisados os dados que o integram.

A cidade inteligente, gerida por dados, é caracterizada pela capacidade de os gestores utilizarem tecnologias próprias para a geração, captação, processamento e análise de dados, visando, entre outros fins, o desenvolvimento de áreas sociais, educacionais, econômicas e ecológicas em relação ao ambiente urbano.

A malha da Cidade Inteligente (Smart City) é integrada por pessoas, instituições e empresas, e pode ensejar diferentes visões. A inclusão de todas as visões é fundamental no processo democrático.

Conectados em redes e pela tecnologia, os cidadãos podem, num processo de transformação, em uma atividade criativa, colaborar com os outros e com o próprio governo para melhorar a vida das cidades, con-

96 SEN, Amartya. Desenvolvimento como liberdade. São Paulo: Companhia De Bolso, 2010. p. 171 
tribuindo para o aperfeiçoamento e a geração de novos serviços públicos, e possibilitando a implementação de políticas públicas sociais.

Da mesma forma, startups e as empresas em geral são importantes participantes da sociedade em rede, pois, valendo-se da economia criativa, podem criar novos aplicativos e tecnologias, com isso gerando melhorias às cidades e aos indivíduos.

As empresas de aplicativos que trabalham com Big Data geram grande impacto nas Cidades Inteligentes (Big Data Business relevantes às Smart Cities), disso advindo a importância de se estudar a questão das políticas concorrenciais ligadas às empresas detentoras de tecnologia e poder econômico manifesto, em especial respeitando-se o princípio da livre concorrência previsto no artigo 170, inciso IV, da Constituição Federal.

A economia criativa, que tem por centralidade os ativos intangíveis, torna-se a principal estratégia de desenvolvimento dos municípios, territórios, estados e países, sendo uma das principais formas de se chegar à sustentabilidade, pois são os únicos recursos que não se esgotam, mas se multiplicam com o uso, gerando não apenas resultados financeiros, mas também resultados sociais, ambientais e culturais.

É necessário serem revistas as políticas públicas concorrenciais no setor tecnológico, de forma a criar novos concorrentes, pois a infinitude dos ativos intangíveis permite uma criação ilimitada. Para tanto, cidades inteligentes necessitam também de pessoas inteligentes, devendo-se, por isso, adotarem-se políticas de democratização da educação.

Tem-se, em conclusão, que restou demonstrada a hipótese inicial, no sentido de que o Big Data, integrando a sociedade em rede e contribuindo para o surgimento da cidade inteligente, possibilita a implementação de uma economia criativa, colaborativa, compartilhada e de livre concorrência, possibilitando a ampliação e concretização de diversas funções sociais da cidade, em especial por meio da implementação de políticas públicas pelos gestores públicos, voltadas em especial para a transformação e a prestação dos serviços públicos, contribuindo assim para o desenvolvimento urbano sustentável e para a cidade mais humanizada.

\section{REFERÊNCIAS}

ABREU, Jacqueline de Souza. Passado, presente e futuro da criptografia forte: desenvolvimento tecnológico e regulação. Revista Brasileira de Políticas Públicas, v. 7, n. 3, 2017.

ARAUJO, Marilene; SANTOS, Maria Celeste Cordeiro Leite dos. O tempo e o espaço. Fragmentos do marco civil da internet: paradigmas de proteção da dignidade humana. Revista Brasileira de Políticas Públicas, v. 7, n. 3, 2017.

ARAUJO, Valter Shuenquener de. Inovação e Administração pública. Rio de Janeiro: UERJ Reg. 2017. Disponível em: <https://www.facebook.com/uerjreg/videos/2065070117045188/>. Acesso em: 11 jan. 2018.

BAGNOLI, Vicente; FRANCESCHINI, José Inácio Gonzaga. Direito concorrencial. In: CARVALHOSA, Modesto (Coord.). Coleção tratado de direito empresarial, 2016. v. 7.

BEZERRA, Tiago José de Souza Lima; MENEZES NETO, Elias Jacob de; MORAIS, Jose Luis Bolzan de. O projeto de lei de proteção de dados pessoais (PL 5267/2016) no mundo do big data: o fenômeno da dataveillance em relação à utilização de metadados e seu impacto nos direitos humanos. Revista Brasileira de Politicas Públicas, v. 7, n. 3, 2017.

BOLÍVAR, Manuel Pedro Rodríguez. Smart technologies for smart governments: transparency, efficiency and organizational issues. Granada: Springer, 2018. v. 24. p. 3.

BORNE, Kirk. Knowledge is power. 11 de abril de 2014. Disponível em: < https://mapr.com/blog/top-10-bigdata-challenges-serious-look-10-big-data-vs/>. Acesso em: 31 out. 2017. 
BRASIL. Lei no 12.965, de 23 de abril de 2014. Disponível em: < http:/ /www.planalto.gov.br/CCIVIL_03/_ Ato2011-2014/2014/Lei/L12965.htm>. Acesso em: 31 out. 2017.

BRASIL. Lei no 13.089, de 12 de janeiro de 2015. Disponível em: <http://www.planalto.gov.br/ccivil_03/_ ato2015-2018/2015/lei/113089.htm>. Acesso em: 29 out. 2017.

BRYNJOLFSSON, Erik; MCAFEE, Andrew. A segunda era das máquinas: trabalho, progresso e prosperidade em uma época de tecnologias brilhantes. Rio de Janeiro: Alta Books, 2015.

CAMPOS FILHO, Cândido Malta. Cidades brasileiras: seu controle ou caos: o que os cidadãos devem fazer para a humanização das cidades no Brasil. São Paulo: Studio Nobel, 1999.

CASE, Steve. A terceira onda da internet: como reinventar os negócios na era digital. São Paulo: HSM, 2017. (Livro digital).

CASTELLS, Manuel. A galáxia da internet: reflexões sobre a internet, os negócios e a sociedade. Tradução: Maria Luiza X. de A. Borges. Rio de janeiro, 2003.

CASTELLS, Manuel. Fim do milênio: a era da informação: economia, sociedade e cultura. São Paulo: Paz e Terra. 1999. v. 3.

CASTELLS, Manuel. Sociedade em rede: a era da informação: economia, sociedade e cultura. São Paulo: Paz e Terra. 1999. v. 1.

CRAWFORD, Kate; SCHULTZ, Jason. Big data and due process: toward a framework to redress predictive privacy harms. Boston College Law, v. 55, n. 1. 2014. Disponível em: <http://lawdigitalcommons.bc.edu/bclr/ vol55/iss1/4>. Acesso em: 30 out. 2017.

EUROPEAN COMMISSION. Opinion 03/2013 on purpose limitation. Disponível em: < http:/ / ec.europa.eu/ justice/data-protection/article-29/documentation/opinion-recommendation/files/2013/wp203_en.pdf>. Acesso em: 31 out. 2017.

EYAL, Nir. Hooked: How to build habit-forming products. New York: Penguin Group. 2014. (livro digital).

FARIAS, Cristiano Chaves de; BRAGA NETTO, Felipe; ROSENVALD, Nelson. Novo tratado de responsabilidade civil. 2. ed. São Paulo: Saraiva. 2017.

FEIGELSON, Bruno; FREITAS, Rafael Véras de; RIBEIRO, Leonardo Coelho (Coord.). Regulaşão e novas tecnologias. Belo Horizonte: Forum, 2017

FERREIRA, Renata Marques; FIORILLO, Celso Antonio Pacheco. Tutela jurídica do whatsapp na sociedade da informação. Rio de Janeiro: Lumen Juris, 2017.

FRAZÃO, Ana. Big data e impactos sobre a análise concorrencial: direito da concorrência é um dos mais afetados pela importância dos dados - parte 1. 29 de novembro de 2017. Disponível em: < https://www.jota.info/ colunas/constituicao-empresa-e-mercado/big-data-e-impactos-sobre-a-analise-concorrencial-29112017>. Acesso em: 10 jan. 2018.

FRAZÃO, Ana. Direito da concorrência: pressupostos e perspectivas. São Paulo: Saraiva, 2017.

FUNDAÇÃO GETÚLIO VARGAS (FGV). O que é uma cidade inteligente?. Disponível em: < http://fgvprojetos.fgv.br/noticias/o-que-e-uma-cidade-inteligente>. Acesso em: 29 out. 2017.

GOMES, Rodrigo Dias de Pinho. Big Data: desafios à tutela da pessoa humana na sociedade da informação. Rio de Janeiro: Lumen Juris, 2017.

GRAU, Eros Roberto. A ordem econômica na Constituição de 1988. 17. ed. São Paulo: Malheiros.

HUNGARO, Luis Alberto. Parceria público-privada municipal: a concretização de funções sociais da cidade: habitação, saneamento básico e mobilidade urbana. Rio de Janeiro: Lumen Juris, 2017. 
INSTITUTO BRASILEIRO DE GEOGRAFIA E ESTATÍSTICA (IBGE). Censo Demográfico 2010. Disponível em: <https:/ / censo2010.ibge.gov.br/sinopse/index.php?dados $=11 \& u f=00>$. Acesso em: 27 out. 2017.

IOSIO, Cristian; VALENTINUZ, Giorgio. Fare impresa com il crowdfunding. Filadelfia: Wolter Kluwer. 2016.

KIRA, Beatriz; PAULA, Pedro C. B. De Paula; ZANATTA, Rafael A. F (Org.). Economias do compartilhamento. Curitiba: Juruá, 2017.

KLEINA, Nilton. Erro no waže deixa trânsito de São Paulo (ainda mais) congestionado. 25 de outubro de 2017. Disponível em: <https://www.tecmundo.com.br/mobilidade-urbana-smart-cities/123450-erro-waze-deixatransito-paulo-ainda-congestionado.htm>. Acesso em: 31 out. 2017.

LONGHI, João Victor Rozatti. Processo legislativo interativo: interatividade e participação por meio das tecnologias da informação e comunicação. Curitiba: Juruá, 2017.

MAYER-SCHONBERGER, Viktor; CUKIER, Kenneth. Big data: a revolution that will transform how we live, work and think. New York: Houghton Mifflin Harcourt, 2013.

MENEZES, Daniel Francisco Nagao; SIQUEIRA NETO, José Francisco. Ensaios de economia criativa e colaborativa e sua regulação. Belo Horizonte: Arraes Editores, 2017.

MOREIRA, Marli. Prefeitura de SP fazparceria com aplicativo do Waze para melhorar o trânsito. 20 de setembro de 2017. Disponível em: <http://agenciabrasil.ebc.com.br/geral/noticia/2017-09/prefeitura-de-sp-faz-parceria-com-aplicativo-waze-para-melhorar-o-transito >. Acesso em: 29 out. 2017.

NASCIMENTO, Barbara Luiza Coutinho do. O direito bumano de acesso à internet: fundamentos, conteúdo e exigibilidade. Rio de Janeiro: editora, 2013 (livro digital).

OLHAR DIGITAL. 4 motivos pelos quais o google compron o waze. Disponível em: < https://olhardigital.com.br/ noticia/4-motivos-pelo-qual-o-google-comprou-o-waze/35180>. Acesso em: 31 out. 2017.

OLHAR DIGITAL. WhatsApp revela número de usuários no Brasil. 29 de maio de 2017. Disponível em: $<$ https://olhardigital.com.br/noticia/whatsapp-revela-numero-de-usuarios-no-brasil/68604>. Acesso em: 11 jan. 2018.

OLIVEIRA, Aroldo Cedraz de (Coord.). O controle da Administração na era digital. Belo Horizonte: Fórum, 2016.

PINHEIRO, Patricia Peck. Direito digital. 6. ed. São Paulo: Saraiva. 2016.

PIRES, Thatiane Cristina Fontão; SILVA, Rafael Peteffi da. A responsabilidade civil pelos atos autônomos da inteligência artificial: notas iniciais sobre a resolução do Parlamento Europeu. Revista Brasileira de Políticas Públicas, v. 7, n. 3, 2017.

POSSAS, M. L. Concorrência Schumpeteriana. In: KUPPER, David; HASENCLEVER, Lia (Org.). Economia industrial: fundamentos teóricos e prática no Brasil. Rio de Janeiro: Campus, 2002. v. 1, p. 415-429.

PWC. Data-driven cities: form concept to applied solutions. p. 4. Disponível em: <https://www.pwc.ru/en/government-and-public-sector/assets/ddc_eng.pdf>. Acesso em: 30 out. 2017.

RAMOS, André de Carvalho. Teoria geral dos direitos bumanos na Ordem Internacional. Rio de janeiro: Renovar. 2005.

REMEDIO, José Antonio; BUONAMICI, Sérgio Claro. Corrupção administrativa: histórico, efeitos danosos e combate por meio de instrumentos de tutela coletiva. Revista Paradigma, Ribeirão Preto, v. 26, p. 147-165, 2017.

SANTOS, Milton. O espaço do cidadão. São Paulo: EDUSP, 2014. v. 8. 
SCHUMPETER, Joseph A. Capitalism, socialism \& democracy. Londres: Routledge. 2013.

SEN, Amartya. Desenvolvimento como liberdade. Rio de Janeiro: Companhia de Bolso, 2010.

SILVA, Marcelo Rodrigues da. Os excessos arrecadatórios nos Crowdfundings doação e recompensa: enriquecimento sem causa? 2017. 76f. TCC (Monografia). São Paulo: USP/FDRP, 2017.

SIXT, Elfriede. Schwarmokonomie und crowdfunding: webasierte finanzierungssysteme im rahmen realwirschaftlicher bedingungen. Bisamberg: Elfriede Sixt, 2014.

SMANIO, Gianpaolo Poggio. Legitimidade jurídica das políticas públicas: a efetivação da cidadania. In: BERTOLIN, Patricia Tuma Martins; SMANIO, Gianpaolo Poggio (Org.). O direito e as políticas públicas no Brasil. São Paulo: Atlas, 2013.

SOUZA, Felipe. Moradores da periferia de São Paulo criam a Ubra para bairro vetado pelo Uber. 15 de março de 2017. Disponível em: <https://g1.globo.com/brasil/noticia/moradores-de-periferia-de-sp-criam-a-ubrapara-bairro-vetado-pelo-uber.ghtml>. Acesso em: 31 out. 2017.

SOUZA, Luciana Cristina. Dignidade humana na webesfera governamental brasileira. Revista Brasileira de Politicas Públicas, v. 7, n. 3, 2017.

SUNDFELD, Carlos Ari. Como compatibilizar legalidade administrativa e inovaşão? 2017. Rio de Janeiro: UERJ Reg. 2017. Disponível em: <https://www.facebook.com/uerjreg/videos/2066124990273034/>. Acesso em: 11 jan. 2018

THE ECONOMIST. The inclusive internet index: bridging digital divides. 2017. Disponível em: < https:// theinclusiveinternet.eiu.com/assets/external/downloads/3i-bridging-digital-divides.pdf $>$. Acesso em: 31 out. 2017.

TOKORO, Nobuyuki. The smart city na the co-creation of value: a source of new competitiveness in a Lowcarbon society. Japan: Springer, 2016.

VANIAN, Jonathan. Why data is the new oil. Fortune, July 2016. Disponível em: <http://fortune. com/2016/07/11/data-oil-brainstorm-tech/>. Acesso em: 31 out. 2017.

VARELLA, Rodrigo Dias. Evolução do conceito de desenvolvimento: do crescimento econômico a expansão das liberdades. 12 de dezembro de 2011. Disponível em: <https://www.youtube.com/watch?time_ continue $=2899 \& \mathrm{v}=$ C7E_1aMPE-E $>$. Acesso em: 29 out. 2017.

VIZZOTTTO, Andrea Teichmann. A recuperação de mais-valias urbanas e os eventos esportivos. In: ALFONSIN, Betânia Moraes; PAGANI, Elaine Adelina; SOMENSI, Simone (Org.) Congresso Comemorativo aos 30 anos do Estatuto da Cidade - II Congresso de Direito Urbano-Ambiental. Porto Alegre: Fundação Escola Superior de Direito Municipal. 2011.

WOLF, Martin. Não devemos entregar nosso futuro às empresas de tecnologia. 16 de novembro de 2017. Disponível em: <http://www1.folha.uol.com.br/colunas/martinwolf/2017/11/1935811-nao-devemos-entregar-nosso-futuro-as-empresas-de-tecnologia.shtml?loggedpaywall>. Acesso em: 10 jan. 2018.

ZYGMUNT, Bauman; LYON, David. Vigilância líquida. Tradução: Carlos Alberto Medeiros. Rio de Janeiro: Zahar, 2013. 
Para publicar na revista Brasileira de Políticas Públicas, acesse o endereço eletrônico www.rbpp.uniceub.br

Observe as normas de publicação, para facilitar e agilizar o trabalho de edição. 